\title{
Climate evolution in the last five centuries simulated by an atmosphere-ocean model: global temperatures, the North Atlantic Oscillation and the Late Maunder Minimum
}

\author{
EduARdo ZORITA $^{1 *}$, HANS VON StORCH ${ }^{1}$, Fidel J. GonZAlEZ-RouCO ${ }^{2}$, UlRich Cubasch ${ }^{3}$,

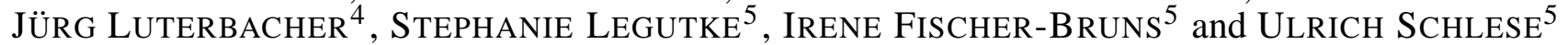 \\ ${ }^{1}$ GKSS Research Centre, Geesthacht, Germany \\ ${ }^{2}$ Universidad Complutense , Depto. de Astrofisica, Madrid, Spain \\ ${ }^{3}$ Institute of Meteorology, Free University Berlin, Germany \\ ${ }^{4}$ National Center of Competence in Research on Climate, University of Bern, Switzerland \\ ${ }^{5}$ Max-Planck-Institute of Meteorology, Hamburg, Germany
}

(Manuscript received May 5, 2003; in revised form January 23, 2004; accepted March 10, 2004)

\begin{abstract}
The main results of a transient climate simulation of the last 500 years with a coupled atmosphere-ocean model driven by estimated solar variability, volcanic activity and atmospheric concentrations of greenhouse gases are presented and compared with several empirical climate reconstructions. Along the last five centuries the climate model simulates a climate colder than mean 20th century conditions almost globally, and the degree of cooling is clearly larger than in most empirical reconstructions of global and North hemispheric near-surface air temperature (MANN et al., 1998; JONES et al., 1998). The simulated temperatures tend to agree more closely with the reconstruction of ESPER et al. (2002) based on extratropical tree-ring chronologies. The model simulates two clear minima of the global mean temperature around 1700 A.D. (the Late Maunder Minimum) and around 1820 A.D. (the Dalton Minimum). The temperature trends simulated after the recovery from these minima are as large as the observed warming in the 20th century. More detailed results concerning the simulated Late Maunder Minimum, together with a spatially resolved historical reconstruction of the temperature field in Europe, are presented. It is found that the broad patterns of temperature deviations are well captured by the model, with stronger cooling in Central and Eastern Europe and weaker cooling along the Atlantic coast. However, the model simulates an intense drop of air-temperature in the North Atlantic ocean, together with an extensive sea-ice cover south of Greenland and lower salinity in North Atlantic at high latitudes, reminiscent of the Great Salinity Anomaly. Also, during the Late Maunder Minimum the intensities of the Golf Stream and the Kuroshio are reduced. This weakening is consistent with a reduced wind-stress forcing upon the ocean surface.
\end{abstract}

\section{Zusammenfassung}

Die wichtigsten Ergebnisse einer transienten Klimasimulation der letzten 500 Jahre mit einem gekoppelten Atmosphäre-Ozean Modell werden vorgestellt und mit verschiedenen empirischen Klimarekonstruktionen verglichen. Das Klimamodell wird hierbei mit historischen Rekonstruktionen der solaren und vulkanischen Aktivität sowie variablen Treibhausgaskonzentrationen angetrieben. Das Klimamodell simuliert während der letzten fünf Jahrhunderte ein nahezu global kälteres Klima in Bezug auf die mittleren Bedingungen des 20. Jahrhunderts. Der Grad der Abkühlung ist hierbei deutlich stärker als innerhalb des Großteils der empirischen Rekonstruktionen der globalen oder nordhemisphärischen bodennahen Lufttemperaturen (MANN et al., 1998; JONES et al., 1998). Die simulierten Temperaturen scheinen jedoch mit den Rekonstruktionen von EsPER et al. (2002), basierend auf außertropischen Baumringchronologien, in einem höheren Maße übereinzustimmen. Das Modell simuliert deutlich zwei globale Temperaturminima um 1700 n.Chr. (Spätes Maunder Minimum) und um 1820 n.Chr. (Dalton Minimum). Die Größe der simulierten Temperaturtrends nach Erholung von diesen Minima entspricht dabei der beobachteten Erwärmung innerhalb des 20. Jahrhunderts. Detailliertere Untersuchungen konzentrieren sich auf das simulierte Späte Maunder Minimum sowie eine räumlich hochaufgelöste historische Rekonstruktion der Temperaturfelder Europas. In diesem Zusammenhang stellt sich heraus, dass die Temperaturabweichungen, einhergehend mit einer stärkeren Abkühlung in Zentral- und Osteuropa und einer abgeschwächten entlang der atlantischen Küste, durch das Klimamodell gut erfasst werden. Auf der anderen Seite simuliert das Modell einen starken Rückgang der Lufttemperaturen über dem Nordatlantischen Ozean zusammen mit einer ausgedehnten Meereisbedeckung südlich Grönlands. Zusätzlich stellt sich ein geringerer Salzgehalt in den hohen Breiten des Nordatlantiks ein, welcher Parallelen zu der Großen Salinitätsanomalie aufzeigt. Des weiteren sind die Intensitäten des Golf- und Kuroshiostromes während des Späten Maunder Minimums abgeschwächt. Diese Abschwächung steht in Einklang mit einem reduzierten Antrieb durch den auf die Ozeanoberfläche einwirkenden Windschub. 


\section{Introduction}

The climate of the last thousand years has recently received considerable attention (MANN et al., 1999; JONES et al., 2001; ESPER et al., 2002), with the longterm goal of estimating the level of natural variability in the absence of large anthropogenic influences. This level of natural variability, either caused by the internal dynamics of the climate system or induced by variations in the external forcing, forms the framework in which the global tropospheric warming observed in the 20th century has to be interpreted. Although the evidence of an anthropogenic influence on the global climate due to the increase of atmospheric greenhouse gas concentrations is strengthening (IPCC, 2001), it is also acknowledged that uncertainties in the typical range of natural climate variations at timescales of centuries still exist. Since the temperature instrumental record is only about 150 years long, an estimation of the natural temperature variations has to be based on climate proxy indicators. In the last years several attempts have been carried out to reconstruct global or hemispheric temperatures of the last centuries with annual or decadal resolution. The best known is perhaps the reconstruction by MANN et al. (1998 and 1999, hereafter MBH98 and MBH99, respectively), based partly on a multiproxy dataset, comprising tree-ring, coral, long instrumental, and ice core records. Other reconstructions based on dendrochronological records have been also published recently (BRIFFA et al., 1998; ESPER et al., 2002; JONES et al., 1998). Also, bore-hole temperature measurements have been shown to contain information of past surface temperatures, that can be retrieved by analyzing the current temperature profile up to about 500 $m$ depth (HUANG et al., 2000). Many other continuous reconstructions of regional character can be found in the literature, not only for temperature but also for other variables, such as precipitation and wind. They can be based on other types of proxy indicators, such as documentary historical evidence, concentrations of certain metals in terrestrial sediments, analysis of stalagmites growth, among others.

In general, the empirical climate reconstructions of the last few centuries identify periods of widespread temperatures lower than today that lasted until about 1850. This period is known as the Little Ice Age (LIA). These lower temperatures reached a minimum around the so called Late Maunder Minimum (LMM; around 1680 to 1710 ) as shown by many European and Asian indicators, a period in which the sun activity, as estimated from the number of sun spots, was reduced (EDDY, 1976). Also in this period, an increased vol-

\footnotetext{
*Corresponding author: Eduardo Zorita, GKSS Forschungszentrum Max-Planck-Str.1, 21502 Geesthacht, Germany, e-mail: zorita@gkss.de
}

canic activity is believed to have occurred (BRIFFA et al., 1999). The LMM, however, does not seem to be restricted to the European region, and other proxy indicators located in other parts of the world also indicate minimum temperatures in these decades (FRITTS and LOUGH, 1985; DRUFFEL and GRIFFIN, 1993; DUNBAR and COLE, 1993; QuinN et al., 1998; HOLMGREN et al., 1999; TYSON et al., 2000; WANG et al., 2001; VILLALBA et al., 2002; YANG et al., 2002; GE et al., 2003). The LIA followed a period of warmer temperatures, the so called Medieval Warm period, in which global temperatures could have attained the levels of the 20th century (JONES et al., 2001).

The different empirical reconstructions disagree somewhat on the level of cooling in the LIA, and in particular during the LMM. In the temperature reconstructions MBH98, based on a comprehensive multiproxy dataset from both the extratropical and tropical regions, the coldest decade was $1696-1705$ over the $\mathrm{NH}$, with $0.35 \mathrm{~K}$ lower annual temperatures relative to the 1902-1980 mean. On the other hand, the North Hemisphere $(\mathrm{NH})$ temperature reconstructions by JONES et al. (1998, hereafter JBBT) or ESPER et al. (2002, hereafter ECS), indicate colder conditions through the LIA; roughly $0.5 \mathrm{~K}$ and $0.7 \mathrm{~K}$ colder than the 1902-1980 mean, respectively. These reconstructions are based on a smaller number of proxy locations (17 and 14, respectively) of mostly dendrochronological time series. Due to the extensive use of dendrochronological data these three $\mathrm{NH}$ reconstructions are probably reflecting more strongly temperature deviations in the extratropical treegrowing season. Finally, temperature estimations based on borehole measurements (HUANG et al., 2000) also indicate global temperatures about $0.7 \mathrm{~K}$ colder than the 20 th century mean. These reconstructions have been recently questioned by MANN et al. (2003).

On the modeling side, the research effort has been more limited to date. A climate simulation of the LMM with an atmospheric General Circulation Model coupled to a slab ocean model with frozen LMM external forcing (SHINDELL et al., 2001) has been carried out. A transient simulation with an energy balance climate model has been also published (CROWLEY, 2000). A simulation of the last millennium with a two-dimensional zonally averaged atmosphere-ocean model has been presented (BERTRAND et al., 2002).

The level of LIA cooling in the CROWLEY (2000) simulation broadly agrees with the MBH99 reconstruction. The level of warming reconstructed and simulated in the last century is much larger than the typical temperature variations in the last millennium, so that the possible anthropogenic influence comes out very clearly (IPCC, 2001). In the series of simulations by BERTRAND et al. (2002), in which the influence of the different external factors is investigated, the global 
warming observed in the last 150 years can be only explained when solar and greenhouse gas forcing are considered simultaneously. However, the level of climate variability in the previous centuries can be coherently explained by the action of solar and volcanic activity (BERTRAND et al., 2002). In both cases the model sensitivity to variations in external forcing can be prescribed externally.

Recently, the global climate model of intermediate complexity CLIMBER2 has been used to assess the relative importance of the different forcing factors for the climate variability in the last millennium (BAUER et al., 2003). The model CLIMBER2, driven by the full external forcing, agrees well with the empirical reconstructions of MBH99 and the simulations by CROWLEY (2000), although the CLIMBER2 decadal and centennial variability is slightly larger. BAUER et al. (2003) also conclude that forcing by land use changes could have played an important role in the last 300 years.

Transient experiments with fully coupled OAGCMs have only been run so far for the last 300 years (CubASCH et al., 1997; HegerL et al., 1997, CubASCH and Voss, 2000). They show that the minimum of radiative forcing during the Dalton Minimum could cause a global cooling. Other transient experiments started in the middle of the 19th century to investigate the question whether mankind or natural causes have been responsible for the observed climate change (STOTT et al., 2000).

The physical mechanisms for the centennial climate variations are much more difficult to identify in empirical reconstructions or in simplified models. The analysis of more comprehensive models can help unveil the physical mechanisms operating in nature. The simulations by CUBASCH and VOSS (2000) indicate that a reduced solar radiation can explain the cooling during the Dalton Minimum. The simulation by SHINDELL et al. (2001) suggests a physical mechanism for the intensification of these colder conditions around the LMM in the European region. This mechanism is related to the reaction of the low-stratospheric circulation to a weaker insolation and to an associated weakening of the winter zonal circulation at midlatitudes in the NH, i.e. a weakened North Atlantic Oscillation (LUTERBACHER et al., 2002b). A version of the same model used by SHINDELL et al. (2001) without a realistic stratosphere fails to simulate the extreme cold conditions in the LMM.

A transient climate simulation with a state-of-the art climate model contributes to clarify the discrepancies of some of the climate reconstructions presented so far and to identify mechanisms that may amplify or reduce the effect of the varying external forcing.

The paper is structured as follows: in section 2 a short description of the model and the external forcing is presented. Section 3 is focused on the main results of the simulation on a global or hemispheric scale: the variability of the global temperature at decadal and centennial timescales and several reconstructions of the North Atlantic Oscillation. Section 4 of the paper is devoted in more detail to the Late Maunder Minimum. The simulated West European temperatures in winter are compared to an empirical reconstruction based on a multiproxy dataset. Finally, possible mechanisms that may be contributing to the temperature anomaly distribution in the Late Maunder Minimum are discussed in view of the model results. The paper is closed by the conclusions.

\section{Model description and experiment}

The global climate model consists of the spectral atmospheric model ECHAM4 (ROECKNER et al., 1996) and the ocean model HOPE-G (Wolff et al., 1997), both developed at the Max-Planck-Institute of Meteorology in Hamburg. In this simulation the model ECHAM4 has a horizontal resolution of T30 (approx. $3.75^{\circ} \times 3.75^{\circ}$ ) and 19 vertical levels, five of them located above $200 \mathrm{hPa}$. The horizontal resolution of the ocean model HOPE-G is about $2.8^{\circ} \times 2.8^{\circ}$ with a grid refinement in the tropical regions, where the meridional grid-point separation decreases progressively to the equator, reaching a value of $0.5^{\circ}$. This increased resolution allows for instance for a more realistic representation of ENSO events. The ocean model has 20 vertical levels.

To avoid climate drift in such a long simulation, additional fluxes of heat and freshwater are applied to the ocean. These fluxes were diagnosed in a coupled spin-up integration with restoring terms that drive the sea-surface-temperature and sea-surface salinity to their climatological observed values. This flux adjustment is constant in time and its global integral vanishes.

In climate simulations with a $1 \%$ annual increase of atmospheric greenhouse gases, the sensitivity of the ECHO-G model lies roughly in the middle of the range of the IPCC simulations, namely $1.70 \mathrm{~K}$ increase at the doubling of the present $\mathrm{CO}_{2}$ concentrations and 3.45 $\mathrm{K}$ in year 2100 A.D.. The sensitivity of the ECHO-G model to changes in the radiative forcing is therefore in line with that of other models.

Two simulations with this model have been carried out. In a control simulation the external forcing was kept constant in time and set to the values of the present climate. The model was integrated for 1000 years. In the second simulation, the period 1550-1990 A.D. was simulated using estimations of three past external forcing factors: solar variability, greenhouse gas concentrations in the atmosphere and an estimation of the radiative effects of stratospheric volcanic aerosols. No changes in the anthropogenic atmospheric aerosol concentrations have been considered. Changes in vegetation cover or land-use have also been neglected. 


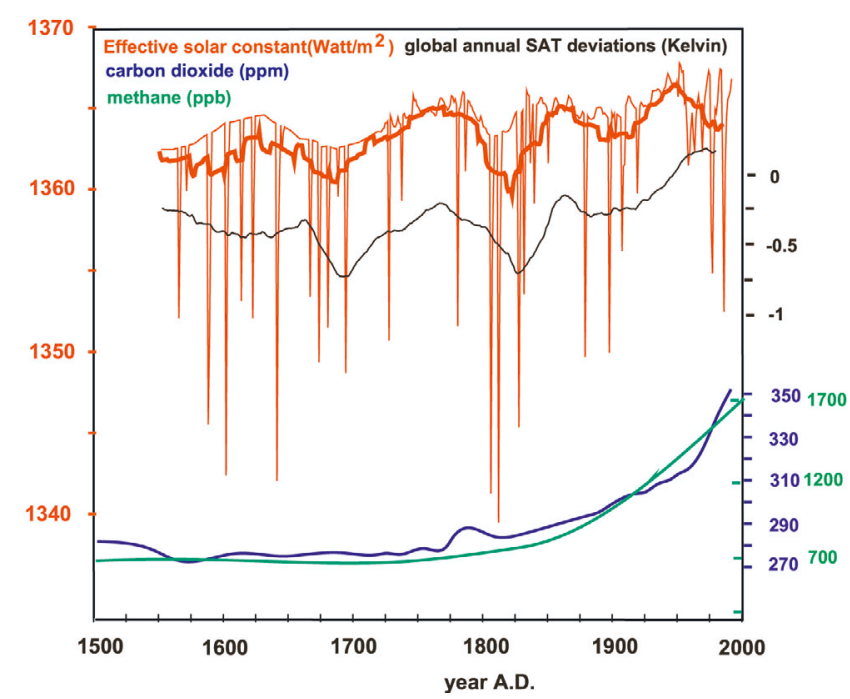

Figure 1: Effective solar constant (solar forcing plus effect of volcanic aerosols; thick red line is a 26-year running mean), concentrations of carbon dioxide and methane used to drive the climate model, and the simulated annual global near-surface temperature, filtered with a 26-year running mean.

The atmospheric concentrations of two greenhouse gases, carbon dioxide and methane, have been estimated from analysis of air bubbles trapped in Antarctica ice cores (ETHERIDGE et al., 1996; BLUNIER et al.,1995). The past variations of solar output have been derived from the values used by CROWLEY (2000). For the period after 1610 A.D., past solar variations are empirically estimated from observations of sun spots (LEAN et al., 1995) and between 1500 and 1610 A.D. they are based on concentrations of the cosmogenic isotope ${ }^{10} \mathrm{Be}$. CROWLEY (2000) used these values to drive an energybalance climate model, i.e. they represent the external net input of short-wave radiation to the climate system. To represent these variations in the ECHO-G simulations these values have been translated to variations in the solar constant, with no wavelength discrimination.

The third external factor is the effect of volcanic aerosols. The estimation of this factor is arguably loaded with the largest uncertainties. From the climatic point of view one of the most important effects of volcanic eruptions is the production of aerosols. These are washed out by precipitation and influence acidity of the ice layers in ice cores. Changes in optical densities of the stratosphere can be thus estimated from ice acidity through a semi-empirical model. However, the ice acidity is also influenced by other factors, such as atmospheric transports, precipitation or dry deposition. The timing and location of the eruption or the time elapsed between eruption and ice formation are also difficult to estimate. Therefore only the most coarse effects of volcanic eruptions can be included. We stick to the same dataset used by CROWLEY (2000) in his energy-balance climate simulation. These are global annual estimations of atmo- spheric optical depth translated to short-wave radiative forcing. As in the case of the solar variability, we translate his numbers to effective variations, global and annual, of the solar constant used in the ECHO-G simulation. The regional and timing details of the eruptions are not communicated to the climate model. Fig. 1 shows the time evolution of these forcing factors as used in the forced climate simulation.

After this simulation was initiated, another estimation, with latitudinal resolution, of stratospheric optical depth in the last centuries has become available (ROBERTSON et al., 2001). As illustration of the uncertainties included in these estimations, these data have been translated in the same way as the CROWLEY (2000) forcing data to net short wave forcing and subsequently globally averaged (not shown). Both datasets show great similarities in the timing of large eruptions and in the periods where eruptions happened more frequently. However, for some individual eruptions the disagreement between both estimations can be of the order of $50 \%$.

\section{Evolution of the near-surface air temperature}

The simulated global near-surface temperature in the forced model integration (Fig 1) exhibits a larger variability than the control run (not shown). Two clear minima, at the end of the 17th century and beginning of the 19th century, are simulated. These minima occur almost simultaneously (after a 2-3 year lag) with known minima in the solar activity, the Late Maunder Minimum and the Dalton Minimum.

Paleoclimatic temperature reconstructions have not targeted the same variable (global, hemispheric, annual or seasonal temperature), so that their comparison is not straightforward (BRIFFA and OSBORN, 2002). For instance, reconstructions based on extratropical dendrochronological evidence can be biased towards extratropical temperatures in the growing season (northern spring-summer), whereas a proxy data set containing much information from tropical regions may underestimate the potentially larger variability in the extratropics. One strategy so far has been to re-scale the different reconstructions to a common framework using scaling factors derived from the instrumental record in the 20 th century, thereby assuming that the proportionality factors are also valid for temperature variations at centennial timescales. To avoid the uncertainties in the rescaling, Fig. 2 shows several original (not re-scaled) $\mathrm{NH}$ temperature reconstructions, together with the annual temperature in the whole $\mathrm{NH}$ and summer temperature in the northern extratropical regions simulated by the ECHO-G model. Both simulated temperature anomalies deviate only slightly, the differences between them being at most of the order of $0.1 \mathrm{~K}$. This is due to two effects in the extratropical summer temperature that tend 


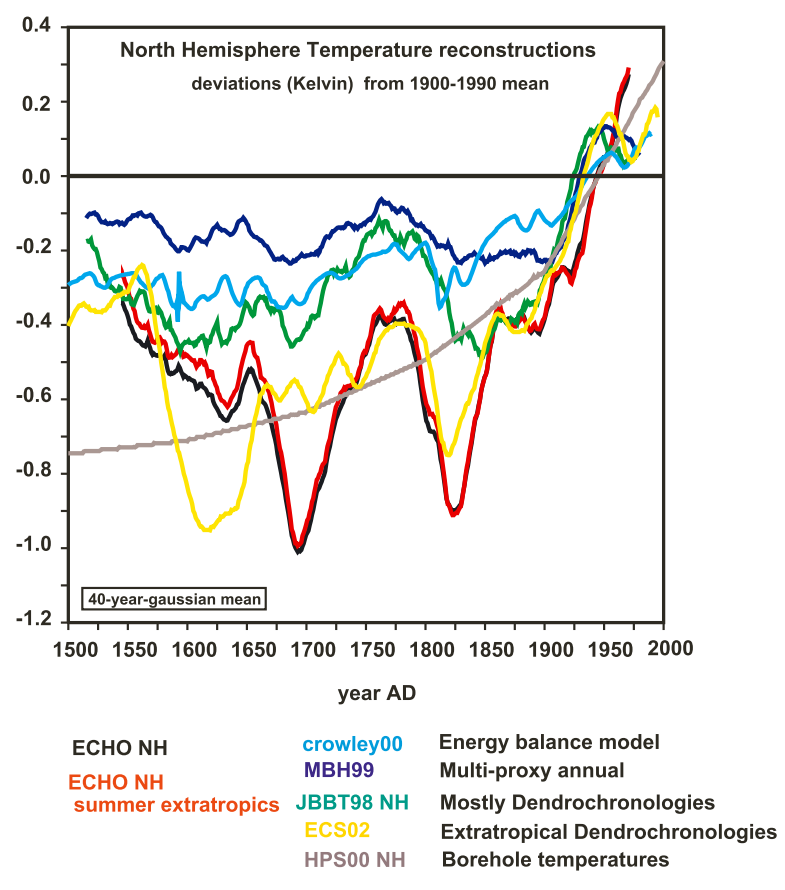

Figure 2: Time series of annual NH and summer northern extratropics mean temperature anomalies (deviations from 1900-1990 mean) simulated by the climate model ECHO-G, compared to a simulation with an energy balance model (CROWLY, 2000), and with reconstructions of $\mathrm{NH}$ mean temperature based on a multiproxy dataset (MBH99), only dendrochronological data (ECS02), various normalized paleo-data of various types records (JBBT98), and on borehole measurements (HPS00). Time series have been smoothed to represent periods longer than 40 years. Note that the individual reconstructions have not been rescaled to represent a common season.

to cancel each other: the centennial variability in summer is smaller than in the annual mean, but the extratropical variability is larger than in the whole $\mathrm{NH}$. The lowest centennial variability is exhibited by the tropical regions, where the difference between annual or summer temperature variability is very small. The simulated mean cooling in the coldest centuries (from 1650 to 1850 , roughly corresponding to what is known as the Little Ice Age) of about $0.6-0.7 \mathrm{~K}$ relative to the 19001990 mean, agrees reasonably well with the extratropical dendrochronological reconstruction of ECS and with the bore-hole estimations (HUANG et al., 2000, hereafter HPS). In particular, the agreement with ECS around the Dalton Minimum and the temperature trend in the last 200 years is remarkable. However, the agreement of the ECS reconstruction and the model in the LMM is far from perfect. The ECS curve indicates colder conditions around 1600 A.D. than in the LMM, in contradiction with other proxy evidence and the JBBT reconstruction. The evolution of the ECS curve in this period (16001750 ) is also at odds with the evolution of estimations of the solar irradiance. It should be pointed out that the
ECS reconstruction is expected to contain little useful information at periods shorter than 20 years (ESPER et al., 2002) and the duration of the LMM in the model is close to this limit. On the other hand, the evolution around the Dalton Minimum, with a similar duration, agrees quite well with the simulation. From the model point of view, the other reconstructions and the energybalance-model simulation of CROWLEY (2000) seem to underestimate the degree of cooling. For instance, when the uncertainty of the MBH99 reconstruction, in terms of two standard error confidence, is taken into account (not shown), the model reconstruction is consistent with the MBH99 estimate before and after the LMM. During the LMM (and the Dalton-Minimum around 1810 A.D.), however, the climate model is suggesting values clearly different from MBH99 reconstruction. As discussed before, this disagreement cannot be circumvented by considering only summer model temperatures. The MBH99 reconstructions could be only representative of the model tropical variability, but the statistical method of MBH99 explicitly targets the annual NH temperature. Model results are thus difficult to reconcile with the MBH99 reconstruction.

The much larger variability at the very-long time scale in the model may have several origins: a too large sensitivity of the model against variations in the external forcing, biases in the external forcing itself, or an underestimation of the temperature changes by the empirical climate reconstructions. The estimation of the global atmospheric optical density based on the Greenland icecores acidity may contain large errors and this might be partially a source for the large LIA and LMM cooling simulated by the model. The sensitivity of the model can be estimated, at shorter timescales, by comparing the centennial trends in the instrumental period with the available instrumental temperature records. Fig. 3 shows the $\mathrm{NH}$ annual temperatures simulated and derived from the instrumental dataset by JONES et al. (1999). For this comparison the ECHO-G data have been decimated to the grid-points that are covered in the JONES et al. (1999) dataset. In the analysis of MBH99 the statistical reconstruction was calibrated against this instrumental dataset and therefore it automatically represents the spatially decimated average temperature. Fig. 3 shows that the model simulations tend to be already too cool in the last 140 simulation years. The linear trends calculated from 1856 onwards support this impression: 0.48 $\mathrm{K}, 0.66 \mathrm{~K}, 0.30 \mathrm{~K}$ and $0.47 \mathrm{~K}$ per century for the instrumental data, ECHO-G, MBH99 reconstructions, and the JBBT98 reconstructions, respectively. However, the interannual standard deviation calculated in the same period, after elimination of the linear trend, indicates that the interannual variability of the model is in line with the observations, whereas the statistical paleoclimatic reconstructions are both somewhat less variable $(0.21$ 


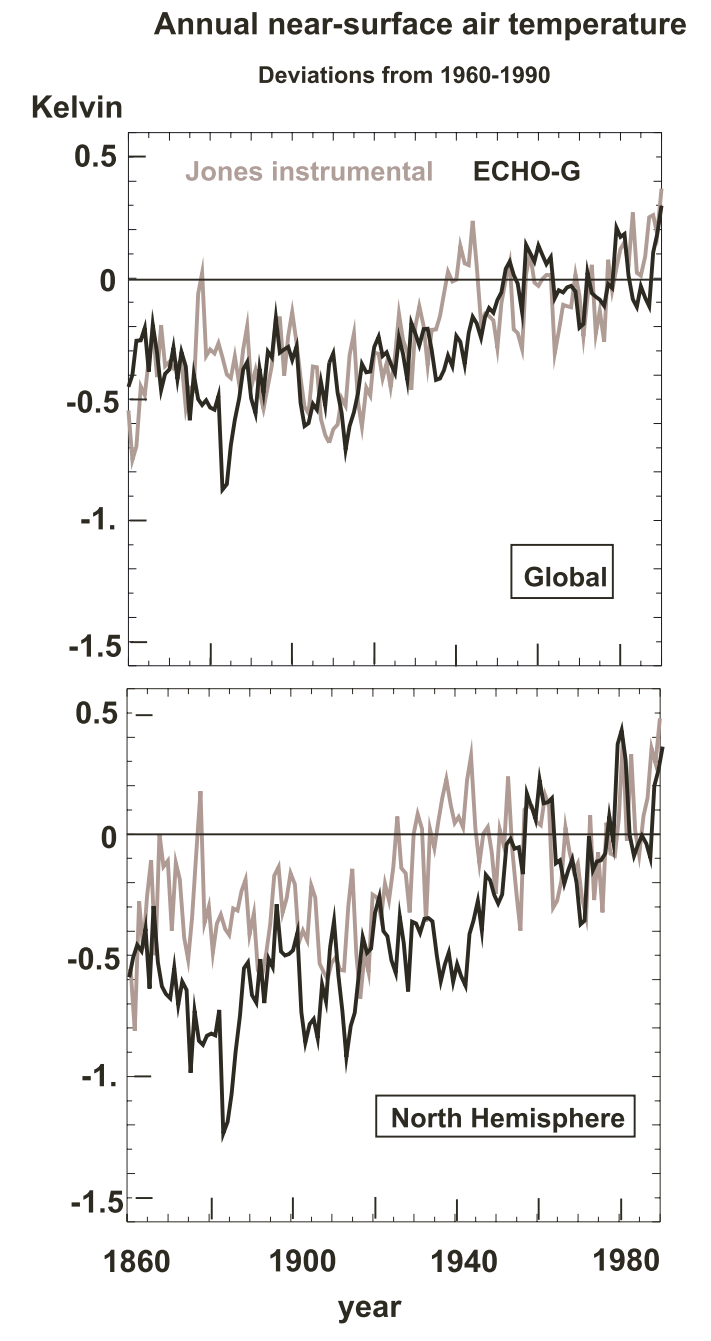

Figure 3: Mean annual near-surface air temperature deviations simulated by the ECHO-G model and derived from the instrumental record (JONES et al., 1999)). The model output has been decimated to match the grid points covered in the observational dataset.

$\mathrm{K}, 0.21 \mathrm{~K}, 0.12 \mathrm{~K}$ and $0.18 \mathrm{~K}$, respectively). It seems, therefore, that the model might be somewhat overestimating the long-term trends caused by variations in the external forcing. This overestimation seems, however, not very severe, but it should be put in the perspective of future climate simulations with other models. The model ECHO-G has also been used to simulate the climate of the next decades under a scenario of $1 \%$ annual increase in the atmospheric $\mathrm{CO}_{2}$ concentrations, similar to the IPCC IS92a scenario. The level of near-surface warming from today's level simulated by this model lies roughly in the middle of the range of the IPCC simulations, namely $1.70 \mathrm{~K}$ at doubling of the present $\mathrm{CO}_{2}$ concentrations and $3.45 \mathrm{~K}$ in year 2100 A.D..

The low-frequency temperature variations in the model are not symmetrically distributed in the Northern and Southern Hemisphere (SH), although the external forcing is symmetric. Fig. 4 reveals the hemispherically

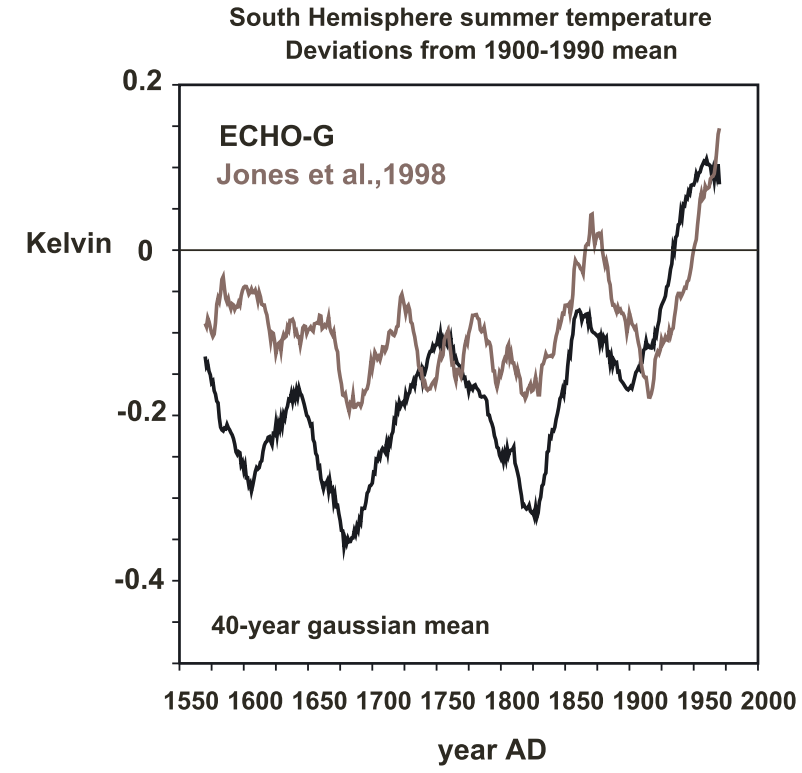

Figure 4: Time series of Southern hemisphere summer air temperature anomalies (deviations from 1900-1990 mean) simulated by the climate model ECHO-G, compared to the dendrochronological reconstructions by JBBT98 (JONES et al., 1998).

averaged air temperature in the summer season for the $\mathrm{SH}$. The centennial variability is clearly lower in the $\mathrm{SH}$ than in the $\mathrm{NH}$, both in the JBBT98 reconstruction and in the ECHO-G simulation, quite probably due to the damping effect of the ocean masses. But, as in the $\mathrm{NH}$, the model tends to simulate colder conditions through the LIA than in the reconstructions. In particular, although the timing of the Maunder Minimum and Dalton minimum agrees, the magnitude of the temperature deviations is about twice as large in the model. Also, a clear lag around 1900 A.D. can be seen between model and reconstruction. However, the temperature trends from 1900 A.D. onwards agree remarkably well.

\section{North Atlantic oscillation}

We turn our attention to one of the most important atmospheric circulation patterns in the extratropics in winter time, the North Atlantic Oscillation (NAO). Usually the spatial pattern of this mode is defined as the leading EOF of the sea-level-pressure (SLP) field in North AtlanticEuropean sector. The corresponding pattern calculated from the climate simulation in the period 1900-1990 A.D. is shown in Fig. 5. This pattern describes the intensity of the low-level westerly winds at midlatitudes and compares quite well with its counterpart obtained from observational datasets (HASTENRATH and GREISCHAR, 2001). Also its fingerprint on the temperature and precipitation fields agree well with observations (ZORITA and GonZÁlEZ-RouCO, 2002). Some differences with 

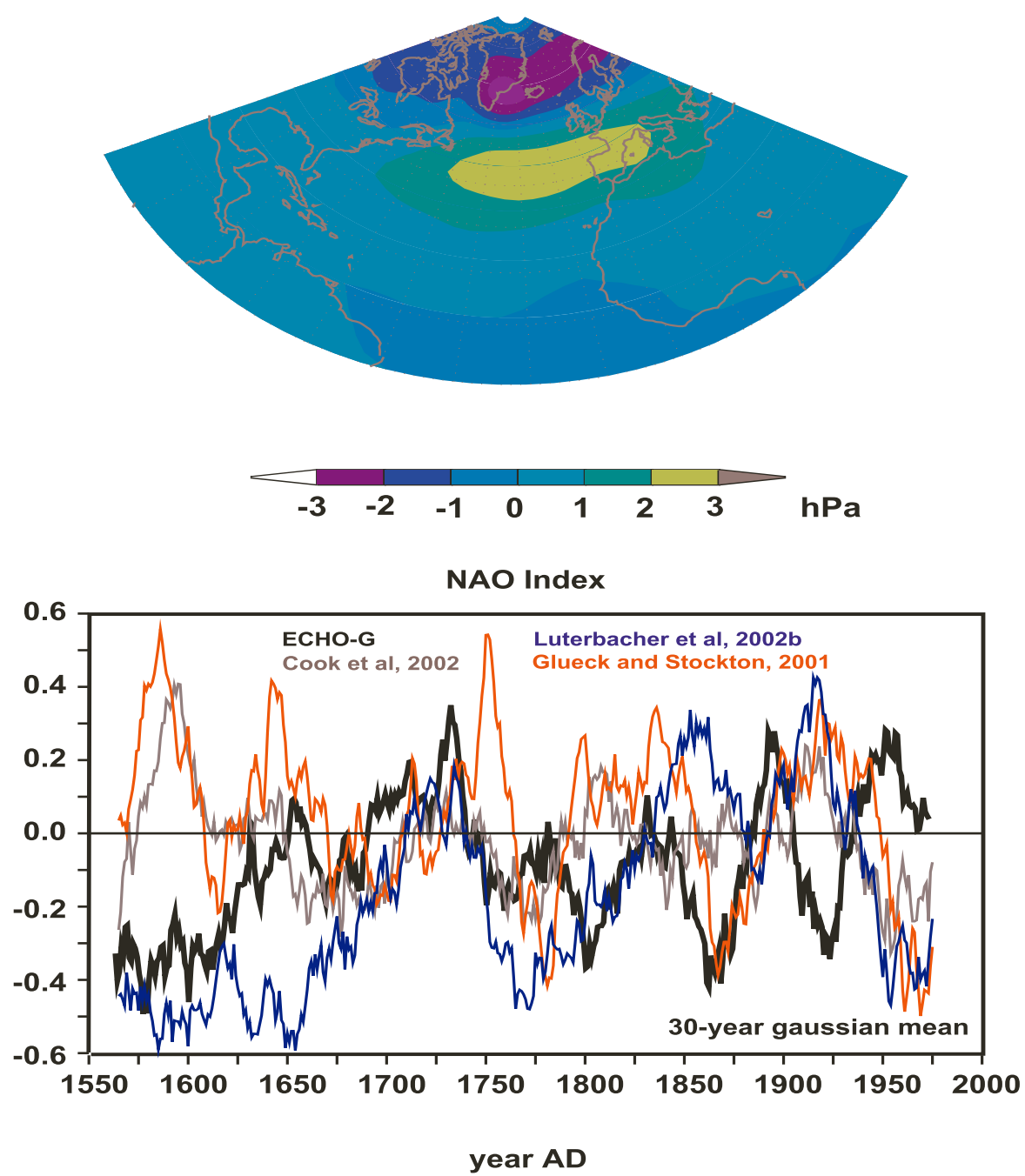

Figure 5: Patterns of the North Atlantic Oscillation as result of an EOF analysis of the simulated SLP fields in winter time in the period 1900-1990 in the North Atlantic-European sector, and the North Atlantic oscillation index, simulated by the model ECHO-G and reconstructed by several authors. The annual indices have been standardized to unit variance and to zero mean in the period 1900-1990

the observations are, however, also evident, for instance, the stronger intensity of the North Pacific Center of action of the Arctic Oscillation in the model (not shown) and a shift of the both centers of action of the NAO towards the Eurasian continent.

The atmospheric circulation presents a high degree of internal variability at high frequencies, and the effect of external forcing on the atmospheric indices is expected to be small. For instance, SLP is one of the variables where the signal-to-noise ratio in climate change simulations is smallest. The effect of anthropogenic greenhouse gas forcing on the NAO is not completely clear (ZORITA and GONZÁLEZ-ROUCO, 2000), although most recent simulations predict a stronger NAO in the next decades. Therefore only a rough agreement - at long timescales - between the evolution of the simulated atmospheric indices and the empirical reconstructions can be expected. The existing empirical re- constructions of the NAO index disagree with one another (SCHMUTZ et al., 2000). Fig. 5 shows the simulated NAO index, calculated as the principal component of the first EOF of the simulated December-February SLP field in the North Atlantic sector, together with three recent empirical reconstruction (LUTERBACHER et al., 2002b; COOK et al., 2002; GLUECK and STOCKTON, 2001). These four indices disagree in several aspects, but they roughly agree in the maximum reached around 1725 A.D. and the subsequent evolution towards lower values of the NAO until 1750 A.D.. Noteworthy is the strong positive trend of all NAO indices throughout the LMM, roughly from 1650 A.D. until 1725 A.D., in contrast to the equilibrium simulation by SHINDELL et al. (2001), where the index remains in a quasi-permanent low index phase during the LMM. From 1750 A.D. onwards the LUTERBACHER et al. (2002b) and GLUECK and StOckTON (2001) reconstructions indicate an evo- 
lution to higher NAOI values. Around 1875 A.D. all NAO indices, with the exception of LUTERBACHER's et al., reach a minimum. From there on, all empirical reconstruction show subsequently roughly the same behavior as they both have been fitted in the instrumental period. Here the simulated NAO index is in clear disagreement with the empirical reconstructions. The question of the relative amount of variance that is related to internal variability and to external forcing can only be ascertained with ensemble simulations. GIORGI and FRANCISCO (2000) have found that the simulated changes in the NAOI in climate change experiments may strongly depend on the internal model variability. It can be reasonably expected that the signal of the external forcing on the atmospheric circulation is only visible in periods with high deviations of the external forcing, e.g. the LMM, the Dalton Minimum and the last decades of the 20th century.

The comparison of the model NAOI with the empirical reconstructions requires a relatively strong lowpass filter to enhance the possible effect of the radiative forcing on the atmospheric circulation relative to the strong interannual variability. However, this low-pass filter masks the behavior of the NAO within the two temperature minima, the LMM and the Dalton minimum. This behavior is described in more detail in the following section.

\section{The Late Maunder Minimum}

We turn now our attention to the winter (DecemberFebruary) air temperature in the decades 1675-1710, where the model simulates an intense global cooling, coincident with the Late Maunder Minimum found in most European proxy indicators (e.g. LUTERBACHER et al., 2001). The Late Maunder Minimum (LMM) was a period at the end of the 17th century of diminished solar irradiance, with several large volcanic eruptions (BRIFFA et al., 1998). In the model simulation a marked minimum of the globally averaged near-surface air temperature occurs around 1690 A.D., which is in agreement with the findings of MANN et al. (1999) and LUTERBACHER et al. (2003) for Europe. In the following a more detailed analysis of the 30 years around this minimum, $1680-1710$ A.D., is presented. Recently, spatially resolved empirical temperature reconstructions for the European region covering this period have been achieved (LUTERBACHER et al., 2004) and this reconstruction is compared with the output of the climate model. In the analysis of the LMM the long-term mean in the period 1550-1850 A.D. is taken as reference mean state to avoid the influence of anthropogenic greenhouse warming.

\subsection{Simulated and reconstructed winter European temperature}

A broad spectrum of early instrumental station temperature and pressure series from London and Paris (MANLEY, 1974; LEgRAND and LEgOFF, 1992; SLONOWSKY et al., 2001) as well as several indexed temperatures and precipitations from various sites are available for the LMM ( WANNER et al., 1995; PFISTER et al., 1999; AlCOFORADO et al., 2000; BARRIENDOS, 1997; Xoplaki et al., 2001; LUterbacher et al., 2001; GLASER, 2001). The latter are derived from documentary evidence and/or from natural archives (narratives, annals, scientific writings, monastery records, direction of cloud movement, wind direction, warm and cold spells, freezing of water bodies, droughts, floods, and information on vegetation). Together with the sea ice conditions off the coasts of Iceland (OGILVIE, 1996) and the ice winter severity in the Western Baltic (KOSLOWSKI and GLASER, 1999) a total of around 20 winter climate time series covering the areas of northwestern, central, eastern and southern Europe are available for the assessment of the LMM. These time series are used to statistically reconstruct large-scale, grid$\operatorname{ded}\left(0.5^{\circ}\right.$ lat. $x 0.5^{\circ}$ lon.) land based winter temperature fields for the LMM for the European land areas $\left(30^{\circ}\right.$ W to $40^{\circ} \mathrm{E} ; 30^{\circ} \mathrm{N}$ to $\left.70^{\circ} \mathrm{N}\right)$. The statistical method is based on an Empirical Orthogonal Function (EOF) analysis of the predictor field (the proxy climate indicators) and of the predictand field (the gridded instrumental air temperature). Standard statistical regression models linking both sets of Principal Components are set up. The statistical relations are calibrated in the period 1901-1960 and validated in 1961-1990. In the validation, the strength of the linear statistical relationship between reconstruction and observation is measured by the Reduction of Error (RE) in each grid point. This is a measure of the quality of the reconstruction between $-\infty$ and 1 (the case for a perfect reconstruction). Positive values of the RE indicate some skill in the reconstruction. After assessment, the statistical parameters are recalibrated in the period 1901-1990 in order to derive seasonal winter temperature fields for the LMM. For a detailed mathematical treatment of the reconstruction method, the reader is referred to LUTERBACHER et al. (2002a, b).

It is believed that $50-80 \%$ of the real variance is recovered by the reconstruction. Over Iceland and northeastern Europe including Russia, the skill is only 20 to $30 \%$, so that there should be some reservation with the reconstruction here. For instance, only sparse information is available for winter conditions in Finland. Some extremely cold winters are mentioned in the historical records, but for many winters it is not known whether they were warmer or cooler than normal 

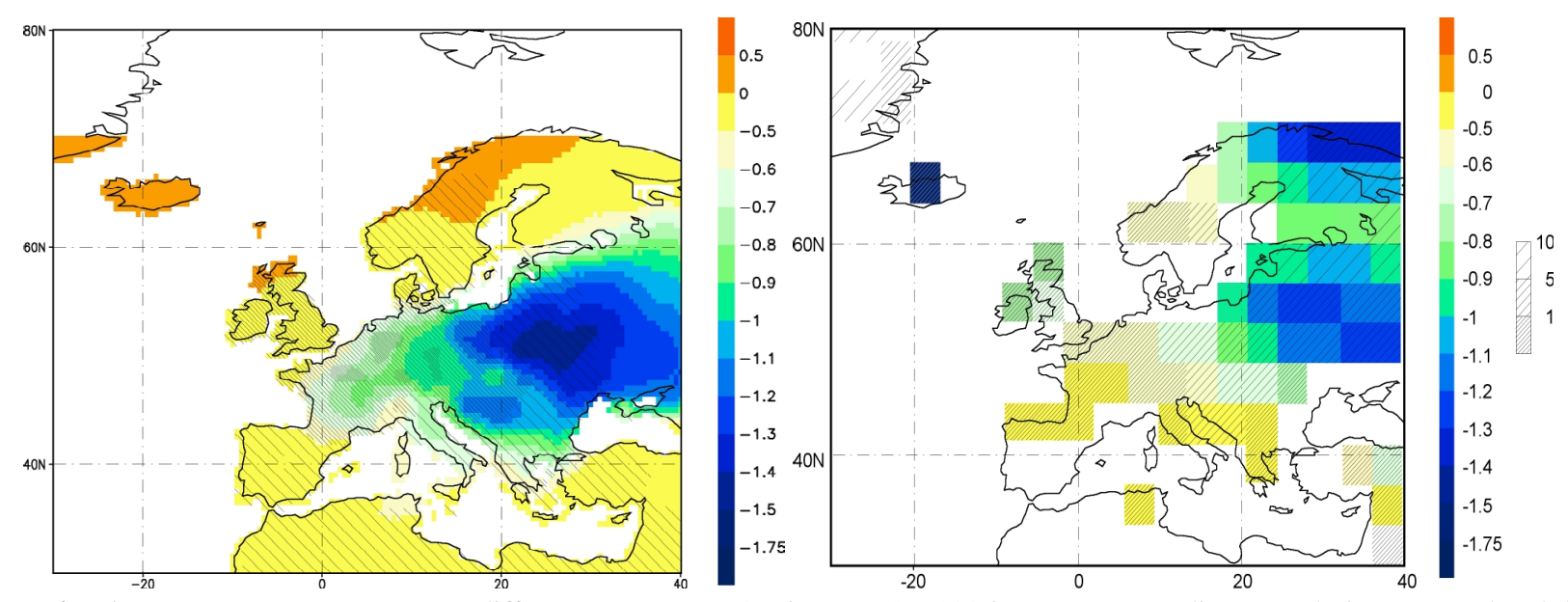

Figure 6: Winter (DJF) mean temperature differences 1675-1710 minus 1550-1800 in Europe according to early instrumental and documentary evidence (a) and model (b). In (a) the statistical model performance (RE) for the LMM winter temperature reconstructions is given by hatching (dense $>0.9$, medium $>0.7$ and light $>0.4$ ). In (b) the statistical significance, as obtained by testing the local null hypothesis of equal means, is indicated by hatching: dense $<1 \%$, medium $<5 \%$ and light $<10 \%$. Units: Kelvin.

\section{(LUTERBACHER et al., 2004)}

Fig. 6a shows the reconstructed winter temperature departures from the 1550-1800 mean, together with the estimated RE. Cooling during the LMM was widespread in Europe, with departures of more than $1.2 \mathrm{~K}$ in Eastern Europe and Western Russia, up to $1 \mathrm{~K}$ in Central and Western Europe and up to $0.5 \mathrm{~K}$ over the Mediterranean, the British Isles and parts of Scandinavia. Up to $0.5 \mathrm{~K}$ higher temperatures were reconstructed only over SE Greenland, Iceland and parts of western Scandinavia. There is evidence of worsening climatic conditions in the Russian North starting at the beginning of the LMM; however the degree of cooling is not given (BORISENKOV, 1994). Warming was estimated to have taken place only in a few locations in northern Norway, Iceland and southeastern Greenland. The confidence in these estimates is low in areas with little historical evidence, in particular Finland, Russia and in the alleged warmer-than-normal spots. According to the RE values, the estimate is representative over Western and Central Europe, South-western Scandinavia, the Balkan and most of the Mediterranean area, while the RE values are rather small over most of Russia, Northern Scandinavia, Iceland and Greenland. Another benchmark for the reconstruction quality is consistency with independent data that was not used in the temperature reconstruction, for instance, Eastern Europe (BOHEMIA and Moravia; BradziL et al., 1994), and The Netherlands, Belgium and Luxembourg (van ENGELEN et al., 2001).

The reconstruction compares well with the modeling result (Fig. 6b), which shows a cooling almost everywhere, with maximum values of $1.2 \mathrm{~K}$ and more in Eastern Europe, and $0.5 \mathrm{~K}$ and more over most of Europe. According to a local t-test, the cooling is systematic, and not due to random variations. It takes place almost ev- erywhere in Europe, Iceland and southern Greenland, with the exception of North-western Norway. Taking into account the local significance in Fig. $6 \mathrm{~b}$ and the RE-values for Fig. 6a, the two diagrams appear to be remarkably consistent, both indicating an enhanced continentality in Europe during the LMM relative to the long term mean.

When comparing simulations and reconstructions at these small spatial scales over continental areas, other feedback processes, such as changes in snow cover may be important. The coarse resolution of the climate model may hamper a realistic representation of the changes in precipitation and snow accumulation over land. The resulting surface albedo changes may cause temperature discrepancies. In this simulation the surface albedo changes in winter in the LMM are, however, generally small (not shown). Only in some areas in Central Asia and Western Russia the surface albedo anomalies attain values of the order of $+0.05-0.1$ (where the modeled mean surface albedo in wintertime is about 0.4 0.5 ), thus contributing to some extent to localized cooling in those areas. However, no broad pattern of increased surface albedo over large continental areas is recognizable in this simulation. The coarse topography of the model makes a comparison of simulated permanent snow cover with historical information on mountain glaciers not meaningful.

\subsection{North Atlantic circulation anomalies and European climate}

To analyze the influence of the atmospheric circulation changes on European temperature anomalies the NAO index has been determined as the difference between the area averaged and normalized mean sea-level pressure anomalies representing the teleconnectivity centers located Northwest of Portugal and over Iceland as in 

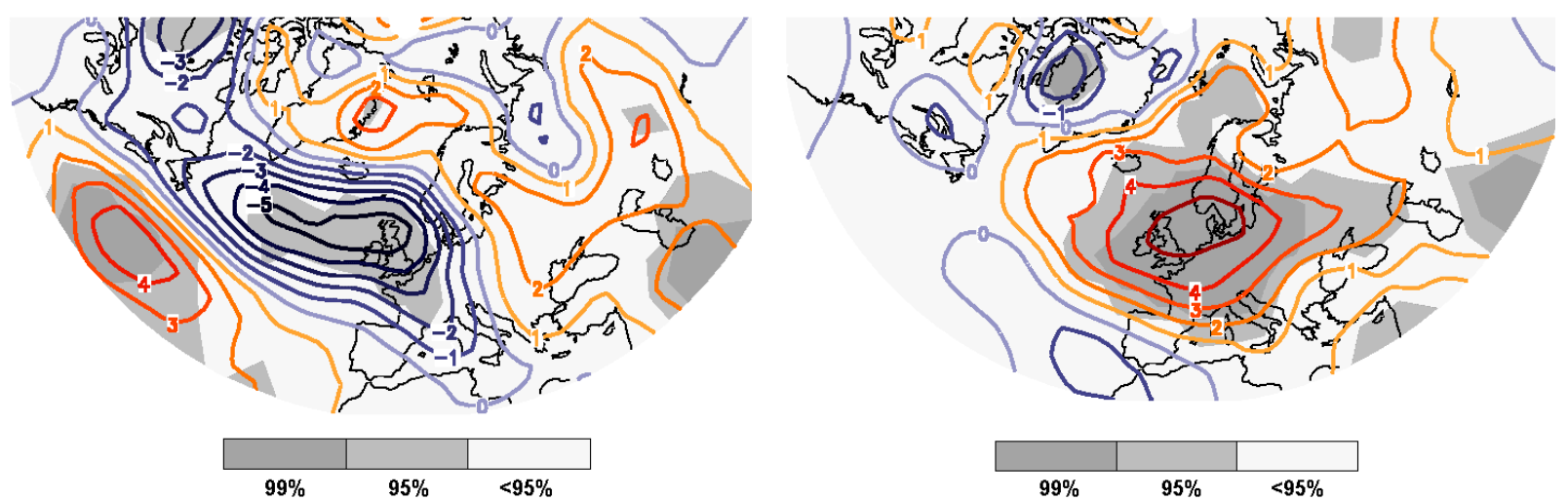

Figure 7: Difference of storm track activity, defined as the 2.5 to 6 day band pass filtered variance of the 500 hPa geopotential height [units: gpm], for the (1671-1684) period ( $\mathrm{NAO}^{-}$, left) and (1685-1708) period $\left(\mathrm{NAO}^{+}\right.$, right) relative to a reference period (1551-1800 except LMM). The grey areas indicate the significance in percent according to a Student t-test.

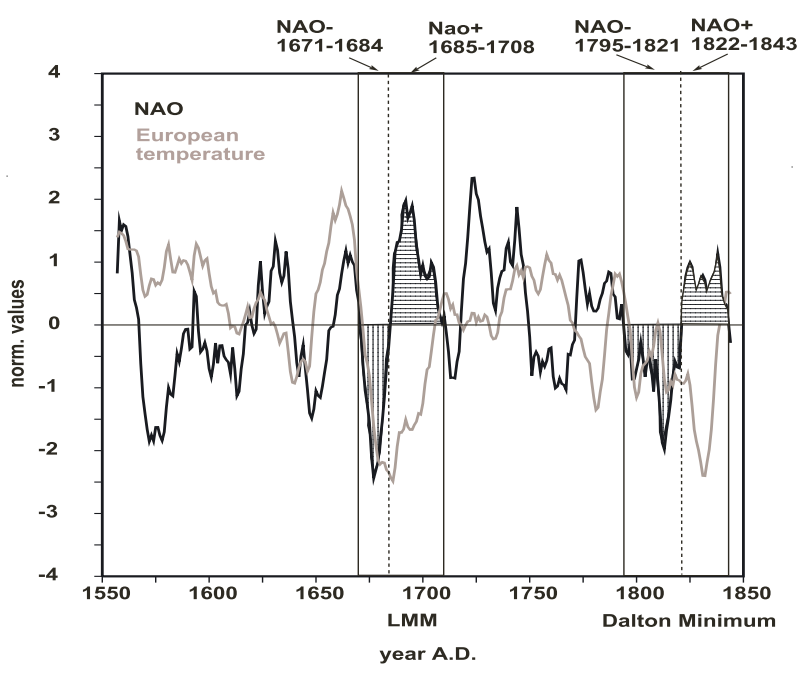

Figure 8: Modeled European (30W-40E, 30N-80N) annual mean near-surface temperature (grey curve) and NAO index (black curve) for the time period $1550-1850$ (11 year running mean). In the period (1671-1684, cooling phase) the NAO index is negative, in the period (1685-1708, warming phase) the NAO index is positive. The Dalton Minimum shows a similar feature.

Ulbrich and Christoph (1999). In Fig. 8 the modeled annual European mean near-surface temperature has been displayed in relation to the modeled NAO index for the time period 1550-1850. During approximately the initial period of the LMM (1671-1684) the NAO index is negative, together with a sharp drop in temperature, indicating that advection of continental cold air dominates in central Europe. This can be confirmed by a significant decrease of storm track activity (defined as the 2.5 to 6 day band pass filtered variance of the 500 hPa geopotential height) in the North Atlantic and West European region (Fig. 7). The NAO then turns positive approximately in the second half of the LMM (16851708) with European warming simultaneously. The enhanced advection of warmer Atlantic air masses contributes to the decay of the LMM, supported by an sig- nificant increase of storm-track activity over the European continent (Fig. 7). This cooling-warming transition can also be verified with the temperature reconstruction of van den Dool et al. (1978). For the Dalton Minimum at the beginning of the 19th century, which is also part of the simulation, a similar behavior can be seen.

\subsection{Global atmospheric and oceanic climate anomalies}

The simulated near-surface temperature anomaly distribution during the LMM is displayed in Fig. 9a. In Northeast Canada, Greenland and the northern North Atlantic a strong cooling of the order of $1 \mathrm{~K}$ and more is evident. Over the NH continents a weaker cooling, of 0.5 $\mathrm{K}$ and more, is prevalent. Over most of the rest of the globe a cooling of up to $0.5 \mathrm{~K}$ is simulated, with regions of warming in the SH. This signal is statistically significant according to a local t-test, for the area north of about $30^{\circ} \mathrm{S}$ (not shown). Thus, the simulated event is a worldwide phenomenon, which is associated with the largest anomalies in the North Atlantic. The overall cooling is consistent with evidence from tropical coral proxy data (Quinn et al., 1998) and the findings for North America (FritTs and Lough, 1985; Dunbar and Cole, 1993), China (WANG et al., 2001; YANG et al., 2002; GE et al., 2003), South Africa (Holmgren et al., 1999) and Southern America (VILlalba et al., 2002).

The air temperature anomaly distribution can also be found almost unchanged in the middle troposphere at $500 \mathrm{hPa}$ height (Fig. 9b), but a qualitative deviation from this spatial structure is observed at $200 \mathrm{hPa}$ (Fig. $9 \mathrm{c})$, where the polar regions actually show positive temperature anomalies with respect to the long-term mean. This behavior has been previously found by SHINDELL et al. (2001) in an equilibrium experiment with an atmospheric model coupled to a mixed layer ocean, forced by LMM solar irradiance. This will be discussed in the next subsection. 


\section{Annual mean air-temperature 1680-1710}

deviations from 1550-1850 mean

Near-surface

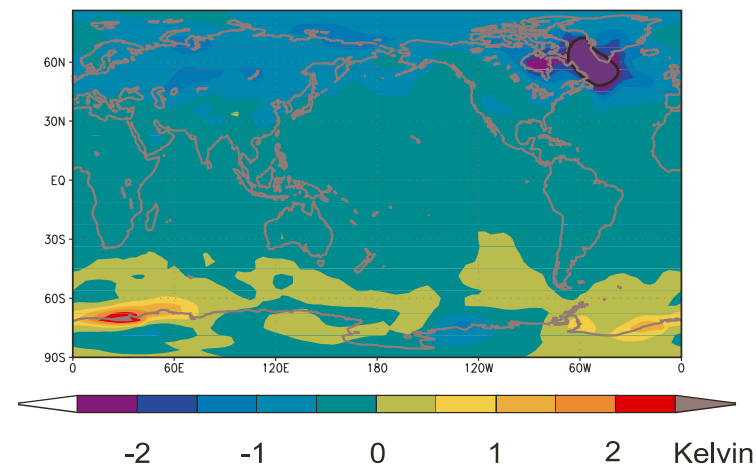

$200 \mathrm{hPa}$

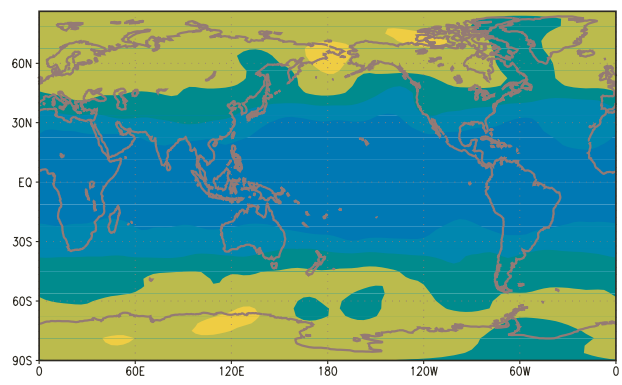

$\begin{array}{llllllllllll}-1 & -0.8 & -0.6 & -0.4 & -0.2 & 0 & 0.2 & 0.4 & 0.6 & 0.8 & 1 & K e l v i n\end{array}$

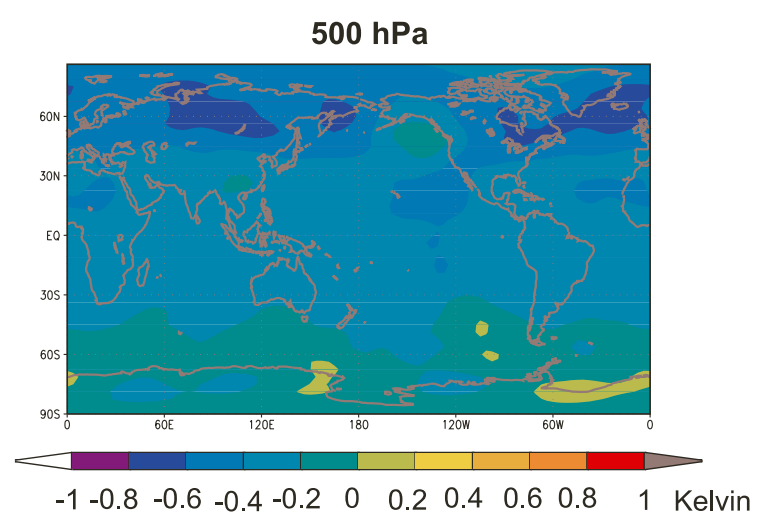

Figure 9: Climate anomalies in the LMM relative to the long-term mean 1550-1850 A.D.: a) annual near-surface air temperature; b) air temperature $500 \mathrm{hPa}$; c) air temperature $200 \mathrm{hPa}$.

in the tropical Atlantic and North Pacific (Fig. 10c). The ice cover and salinity anomalies in the North Atlantic are reminiscent of the Great Salinity Anomaly (GSA) observed in the North Atlantic in the late 1960's and 1970's. According to MYSAK et al. (1990) hypothesis the ice cover associated to the GSA could have its origin in an excess of freshwater input into the North Atlantic through increased precipitation minus evaporation in the North Atlantic-Labrador Sea sector. The fresher water masses would freeze more easily. The ice produced in this way could be then advected to regions where ocean convection takes place, thereby affecting the deep water production. Other mechanisms have been proposed to explain extreme GSA and ice cover events simulated in coupled climate models (Hall and STOUFFER, 2001). In their simulation, anomalously strong and persistent northerly winds cause an increased ice export from the Arctic Ocean that subsequently melts and freshens the North Atlantic waters.

The large salinity anomalies at $100 \mathrm{~m}$ depth in the Tropical Atlantic are restricted to the upper ocean layers and are not visible at $450 \mathrm{~m}$ depth. They are not related to clear freshwater fluxes at the surface nor to horizontal advection by ocean currents, so that they are probably associated with a deepening of the thermocline in the Eastern Tropical Atlantic.
Salinity at $100 \mathrm{~m}$ depth is lower than the long-term mean in the North Atlantic with clear positive anomalies 

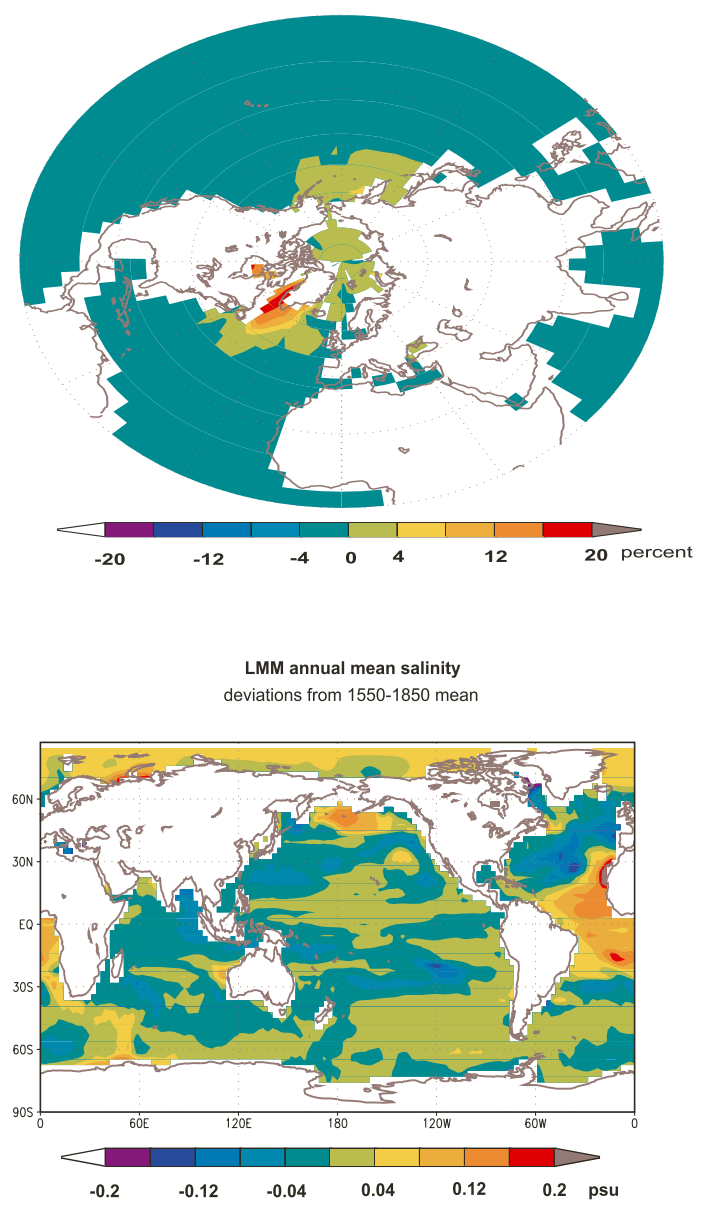

\subsection{Atmosphere-ocean feedback mechanisms involved in the Late Maunder Minimum}

In the decades around the LMM the near-surface temperatures are almost everywhere lower than the long term mean, in accordance with the reduced solar irradiance and increased volcanic activity. The ECHO-G model responds to the equivalent solar forcing clearly more strongly than the energy balance model of CROWLEY (2000). This holds even if the North Atlantic sector at high latitudes is left out when calculating the global mean temperature change. The simulated temperature change approaches the result of CROWLEY only when the high latitudes are excluded to calculate the mean. The overall sensitivity of the ECHO-G model to slow changes in the radiative forcing, as inferred from climate simulations for the 21 st century, is in line with that of other models, and similar to the one prescribed in the energy balance model of CROWLEY (2000). In the LMM the changes in the radiative forcing are of a shorter time scale, and the stronger cooling at high latitudes simulated by ECHO-G may indicate that an equilibrium energy balance model may not be able to capture the feed-back mechanisms at high latitudes.

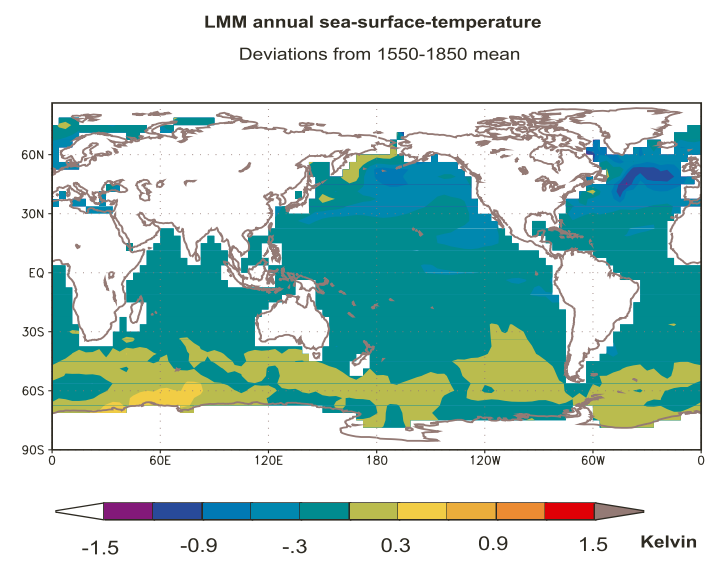

Figure 10: Climate anomalies in the LMM relative to the longterm mean 1550-1850 A.D.: a) sea-ice coverage (percent)); b) seasurface temperature; c) salinity at $100 \mathrm{~m}$ depth.

The global distribution of SST or near-surface temperature anomalies during the LMM is, apart from the positive anomalies in the SH, compatible with the weaker solar insolation and stronger volcanic activity. At high latitudes in the northern ocean basins the temperature drop is higher than on average, specially in the North Atlantic off South Greenland. The SST anomaly distribution is indicative of a change in the strength of the Western Boundary Current systems, the Golf Stream and the Kuroshio as shown in the intensity of the mean annual stream function at 100 meter depth (Fig. 11).

The spatial stream function patterns describe in both basins the strength of the gyre circulation. Both stream indicators show that in the LMM these current systems were weaker than in the long-term mean. They are also coupled in time to the annually averaged global temperature and therefore to the effective radiative forcing. Fig. 11 also shows, as a measure of the average atmospheric forcing on the ocean surface, the annually averaged wind-stress curl, spatially averaged over the ocean grid-points in each basin (the basin integral of the ratio of the wind stress over the Coriolis parameter yields a similar picture). To first order, apart from the globally reduced solar input that causes an almost global cooling, the explanation for the simulated near-surface tem- 


\section{Western Boundary Current Intensity, $100 \mathrm{~m}$ depth}

Deviations from 1550-1850 mean
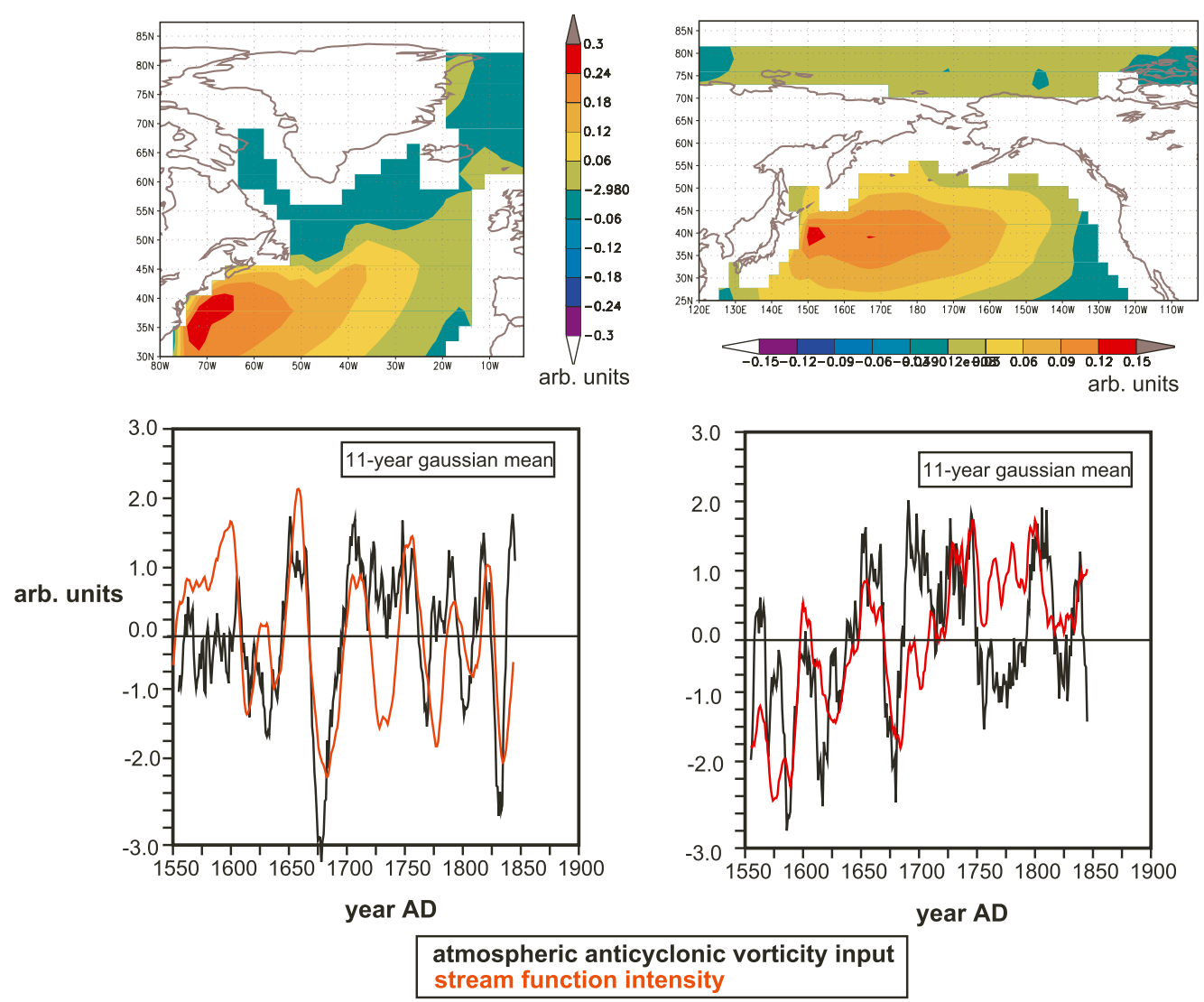

Figure 11: Leading EOF patterns of the annual stream function at $100 \mathrm{~m}$ depth in the North Atlantic and North Pacific (positive, anticyclonic circulation), together with the associated principal components in the period 1550-1850 A.D. and the annual wind stress vorticity (positive, anticyclonic) averaged over the ocean-gridpoints in the respective ocean basins. Anomalies are relative to the long-term mean 1550-1850 A.D..

perature anomalies in the LMM at high latitudes would involve the weakening of the Western Boundary systems as a response to the atmospheric circulation.

The atmospheric circulation would then have changed as a response to changes in the radiative forcing. Such a mechanism has not been completely established yet. In general, scenario simulations for the next century (increasing radiative forcing) tend to indicate a strengthening of the atmospheric zonal indices (SHINDELL et al., 1999; FYFE et al., 1999; ZORITA and GONZÁlEZ-RouCO, 2000). At shorter timescales, the LMM (decreased radiative forcing) simulations by SHINDELL et al. (2001) show a weakening of the NAO index. In the present simulation, with an interactive three-dimensional ocean, this is reflected in a reduced anticyclonic vorticity input to the ocean surface in the subtropical gyres, slowing the western boundaries currents and thereby intensifying the temperature drop at middle and high latitudes in the Northern Ocean basin.

The connection between the equator-to-pole temper- ature gradient at $200 \mathrm{hPa}$ and the anticyclonic vorticity input is illustrated in Fig. 12. The temperature gradient evolves very nearly in phase with the wind-stress forcing before and during the LMM, although the agreement is not so good in later decades, specially during the Dalton Minimum (not shown). According to the results of SHINDELL et al. (2001), an increased solar insolation should cause a stronger warming of the Tropical higher troposphere than of the lower polar stratosphere, thereby intensifying the zonal wind in the lower stratosphere. This enhanced zonal wind would be more effective in reflecting equatorwards the vertically propagating gravity waves from the lower troposphere, intensifying the northward momentum flux in the troposphere, i.e. leading to a stronger zonal index. This higher wave reflectivity at the tropopause hinders also the vertical heat transport by waves into the stratosphere. The situation with reduced solar insolation should be reversed. This version of the ECHO-G model, however, lacks a realistic representation of the stratosphere, both dynamical and chem- 


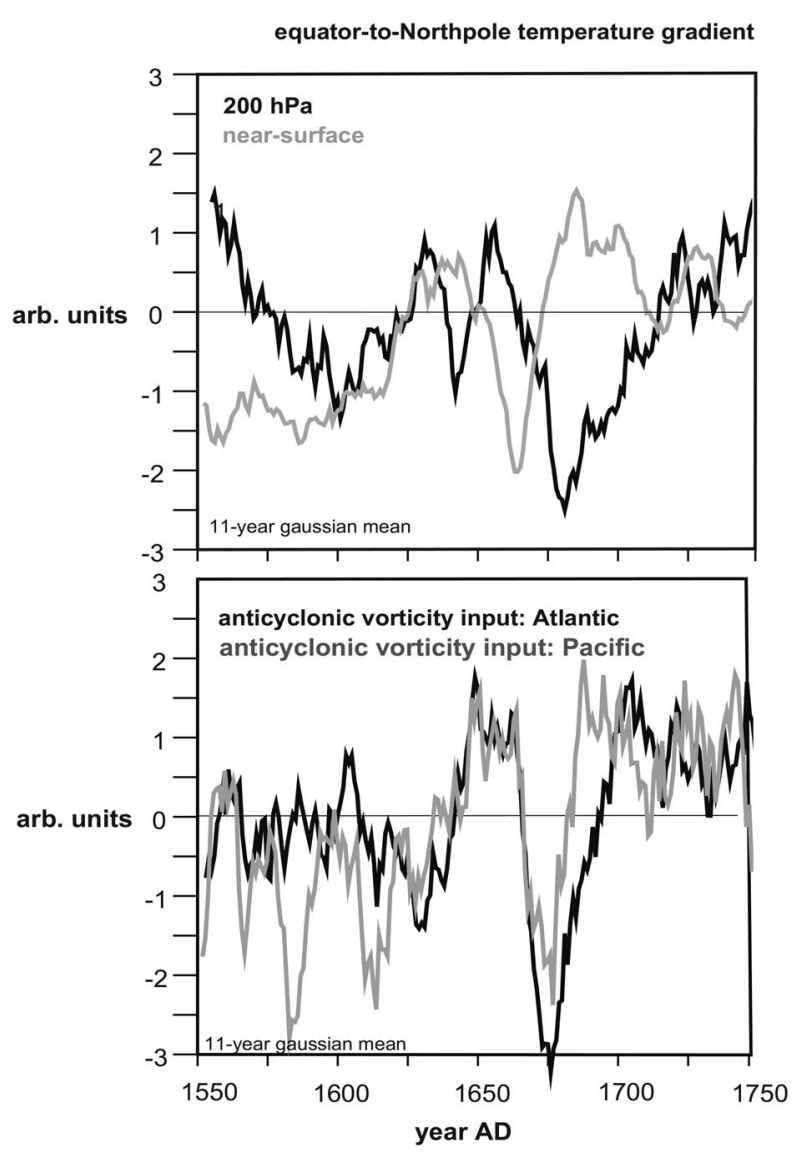

Figure 12: Zonally averaged annual equator-to-pole temperature gradient in the $\mathrm{NH}$ at $200 \mathrm{hPa}$ height compared to the annual wind stress vorticity (positive, anticyclonic) averaged over the ocean grid-points in the North Atlantic and North Pacific basins. Anomalies are relative to the long-term mean 1550-1850 A.D.. Time series are normalized by their own standard deviation.

ical, and it is therefore surprising that this mechanism could be also responsible for the reduced temperature gradient at $200 \mathrm{hPa}$ in the present simulation. But otherwise, the positive temperature anomalies at $200 \mathrm{hPa}$ in the polar regions (Fig. 9c) are difficult to reconcile with the reduced solar insolation in the LMM.

When the pattern of LMM simultaneous temperature anomalies (near-surface and at $200 \mathrm{hPa}$ ) is zonally averaged, it is possible to explain about $30 \%$ of the common interannual variability in the whole forced simulation and just $15 \%$ of the common interannual variability in the control run. It seems therefore, that the variations in the solar insolation may be at least partially responsible for the contrasting meridional temperature gradients near the surface and at $200 \mathrm{hPa}$, although this simultaneous anomaly pattern also appears, albeit less frequently, in the control simulation.

We now shortly explore other possible oceanic mechanisms that may be involved in the negative temperature anomalies in the northern high latitudes during the

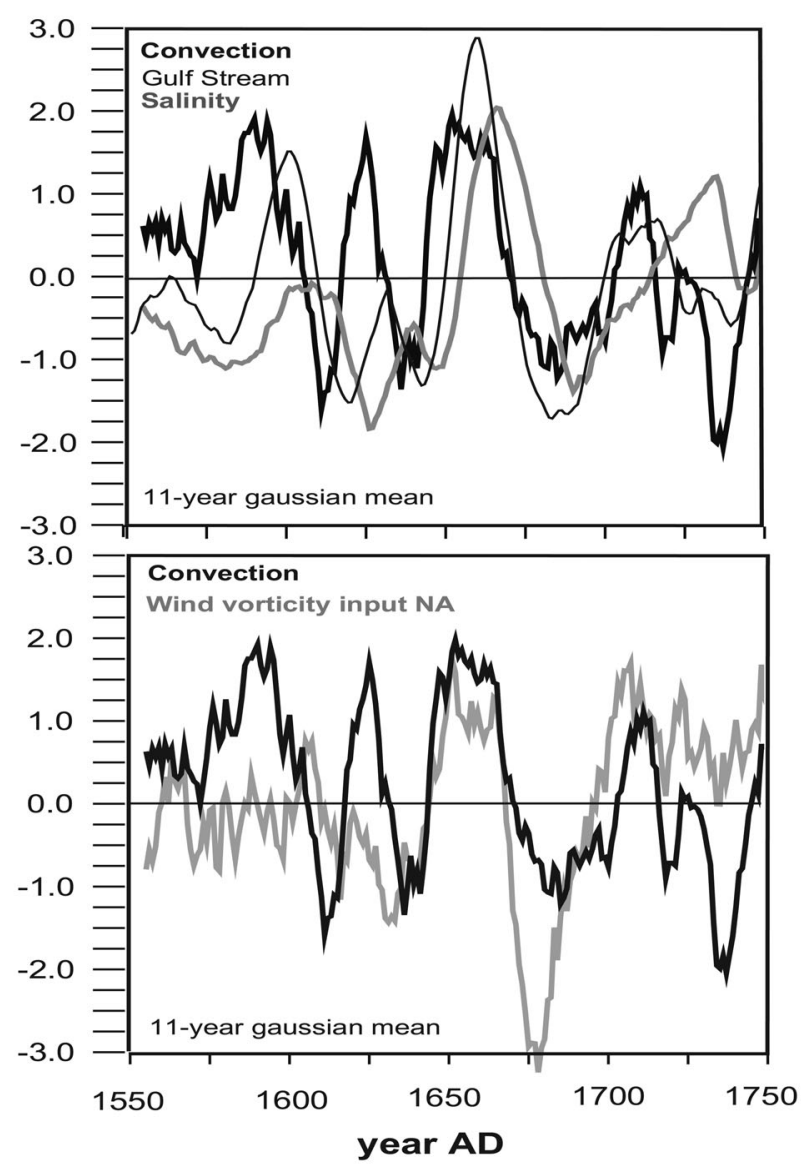

Figure 13: Top: annual potential energy released in oceanic convective events averaged over the high latitude North Atlantic and Nordic Seas; annual salinity at $100 \mathrm{~m}$ depth averaged over the high-latitude North Atlantic together with the Gulf Stream intensity indicator of Fig. 11; Bottom: Ocean convective activity in the North Atlantic (as in top) together with the wind-stress vorticity input into the North Atlantic ocean. Anomalies are relative to the long-term mean 1550-1850 A.D.. Time series are normalized by their own standard deviation.

LMM in the North Atlantic basin, namely deep water production in the North Atlantic. Fig. 10c indicates that salinity at $100 \mathrm{~m}$ depth was lower than the long-term mean in most of the North Atlantic ocean. This could be an indication of reduced water densities in the nearsurface layers, conductive to a reduced oceanic convection in the North Atlantic at high latitudes. The variations in oceanic convective activity in the North Atlantic do show some connection with the LMM. Fig. 13a exhibits the time series of the potential energy released in convective events, averaged in the Northern Seas at high latitudes and the time series of the averaged salinity at $100 \mathrm{~m}$ depth, also spatially averaged in the North Atlantic at high latitudes. For comparison purposes this figure also shows the intensity of the Gulf Stream, as defined previously. The evolution of the convective activity precedes the variations of salinity and of the strength of the Gulf Steam in the LMM, being an indication that 
Ice cover
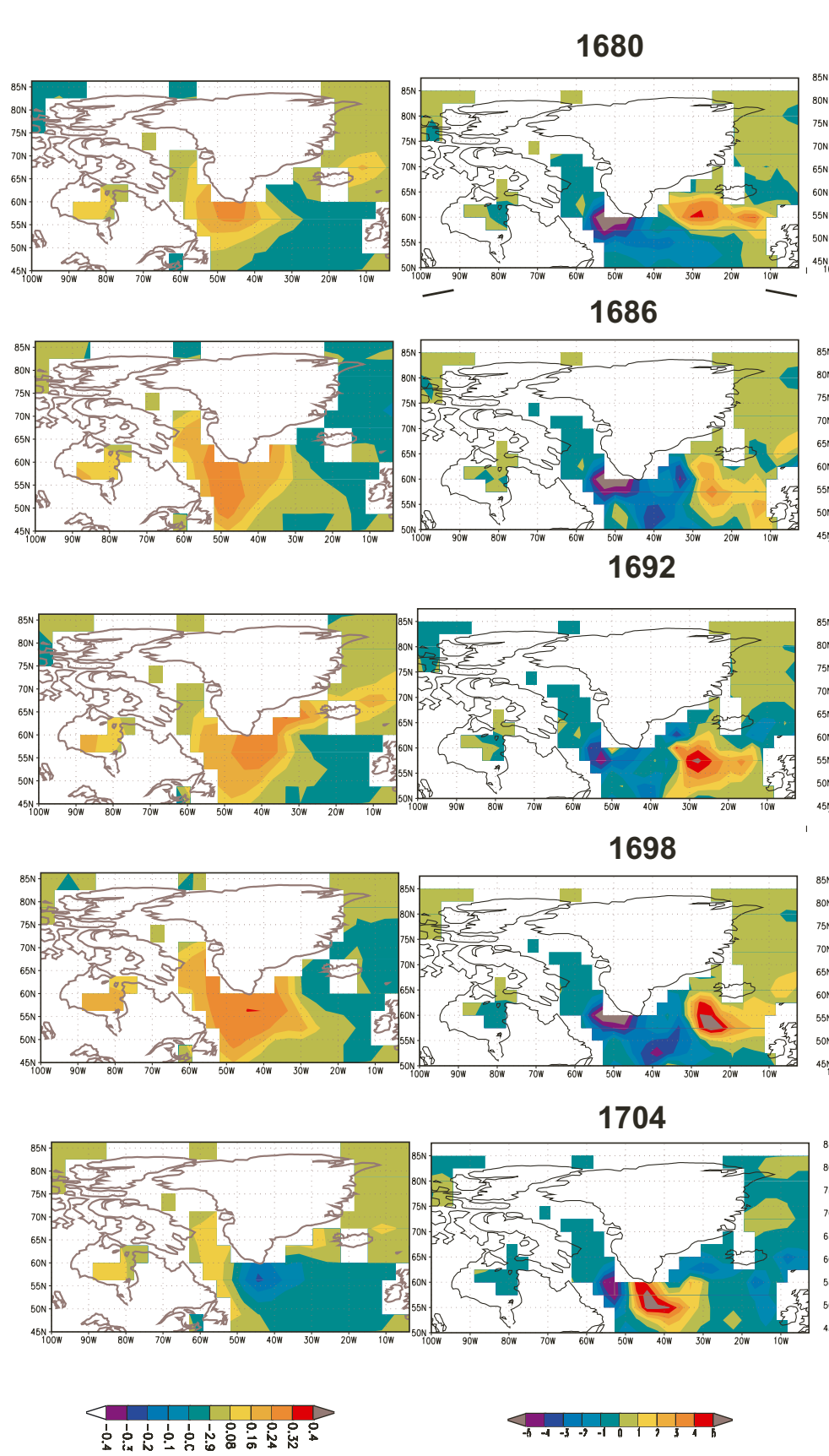

1698

1704

Convective activity

1680

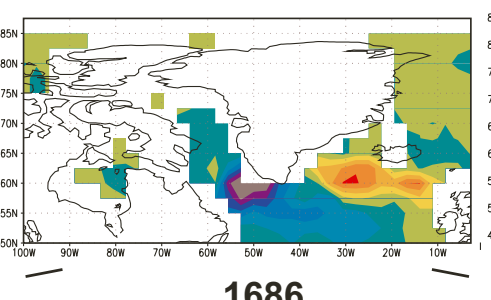

1686
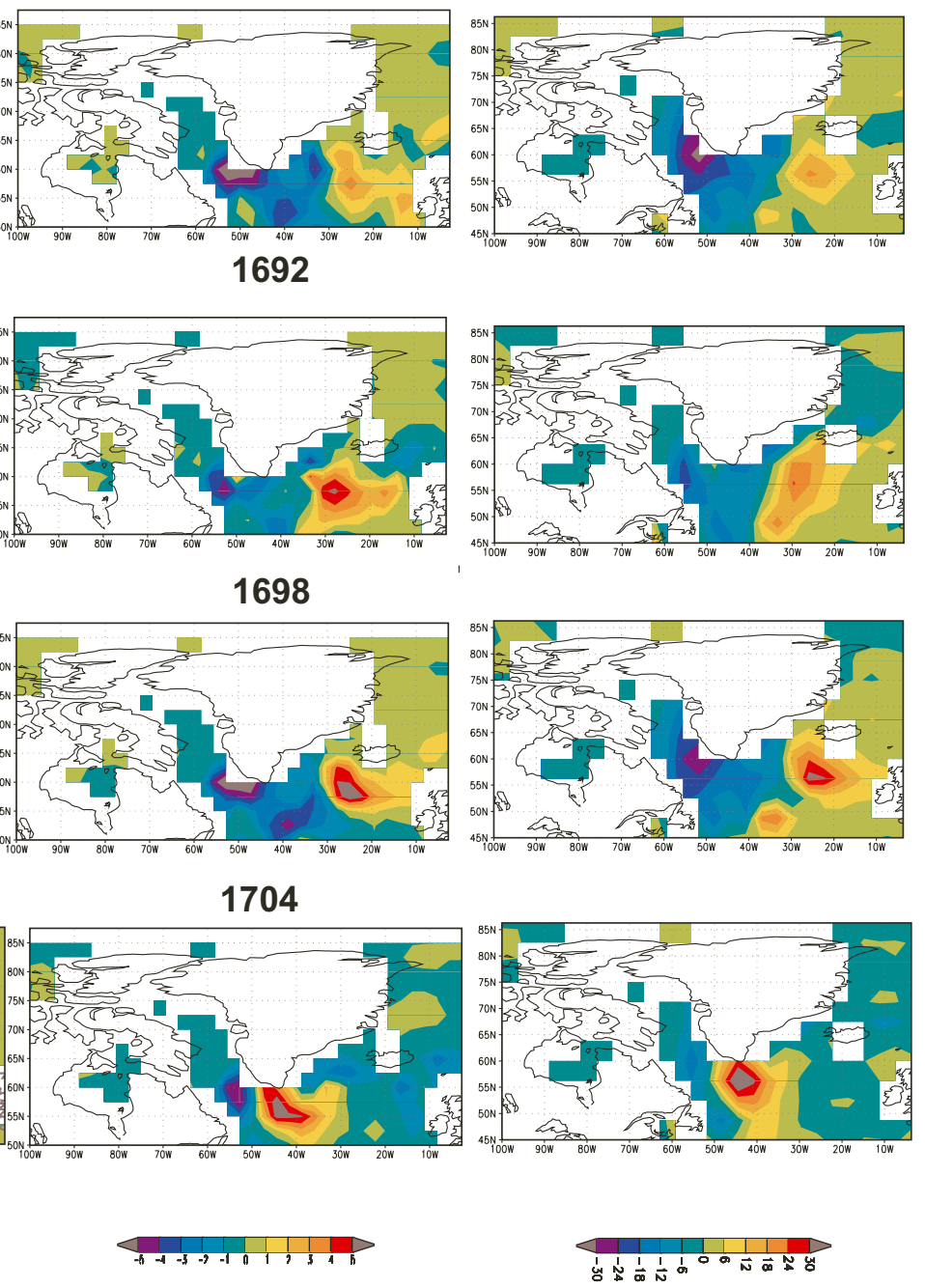

Figure 14: Anomalies of annual sea-ice cover, potential energy released by oceanic convection $\left(\mathrm{W} / \mathrm{m}^{2}\right)$ and sensible heat flux $\left(\mathrm{W} / \mathrm{m}^{2}\right.$, positive into the atmosphere) at selected years during the Late Maunder Minimum in the North Atlantic. The fields have been previously smoothed in time with a 5-year running mean filter.

the convective activity is also contributing to variations of the Gulf Stream intensity. However, the variations of salinity seem to be just a response of either convective activity and/or variations in the intensity of the Gulf Stream. Also, the amplitude of the variations in the convective activity before and during the LMM are large, but not exceptional, whereas the anomalies of the Gulf Stream intensity and the wind-stress forcing reach out- standing levels in these decades. Similar conclusions can be drawn regarding sea-surface temperature in the North Atlantic, since salinity and temperature evolve around the LMM in phase, as it could be expected by an advective mechanism. The question remains what the origins of the variations in the convective activity are.

The ice cover anomalies south of Greenland throughout the LMM are formed locally and do not seem to be a 
result of ice advection from the Arctic along the Greenland coast. This is shown in selected snapshots during the LMM of the simulation in Fig. 14. In this figure the corresponding anomalies of convective activity are also shown. The ice cover anomalies are closely anticorrelated, in time and space, to anomalies of convective activity, indicating that probably the upward oceanic heat flux is locally driving the ice formation. The seasurface salinity anomalies themselves do not seem to be large enough to influence decisively the formation of ice, since a reduction of $0.2 \mathrm{psu}$ is linked to an increase of just $0.01 \mathrm{~K}$ in the freezing point of sea-water.

An interesting aspect of the climate variations around the LMM is the recovery of the zonal circulation, and therefore of the anticyclonic vorticity input, to positive values before the end of the LMM. This is consistent with the trend of the NAO index existing in all empirical reconstructions (Fig. 5). This can also clearly be seen in Fig. 13b, where the anomalous vorticity input becomes anticyclonic before 1700 A.D., while the solar radiation has barely recovered and the global temperature minimum has not yet occurred. Also apparent is the decoupling of the vorticity input in the North Atlantic and North Pacific basins from the temperature gradient at $200 \mathrm{hPa}$ at the outset of the LMM around 1700 A.D. (Fig. 12). A speculative mechanism that may explain this behavior is the reaction of the atmospheric circulation to the sea-surface-temperature anomaly pattern created during the first stages in the LMM. Due to the weakening of the Western Boundary currents (and of the convective activity in the North Atlantic) the meridional temperature gradient is increased and this could possibly tend to intensify the atmospheric zonal circulation, i.e. to be a negative feedback to the original forcing. After some lag this negative feedback would overshoot and tend to bring the advective negative SST anomalies at high latitudes to an end. This mechanism can only be ascertained by additional stand-alone experiments with the atmospheric submodel forced by LMM ocean surface fluxes. In general, simulations with atmospheric GCMs driven by SST anomalies have not yielded a clear picture of the response of the atmospheric circulation. However, during the LMM the model simulated extensive sea-ice cover anomalies in the North Atlantic that allow for much lower surface temperatures and reduced heat-flux from the ocean (Fig. 14).

The broad picture that emerges from this analysis is that variations in the solar insolation around the LMM influence the atmospheric circulation, initially favoring a low zonal index. The reduced anticyclonic vorticity wind forcing associated to a low zonal index modulates the Western Boundary currents and in the North Atlantic possibly the intensity of oceanic convection, intensifying the sea-surface temperature and salinity drop at higher latitudes, specially in the North Atlantic. The recovery of the solar insolation to long-term values should bring these climate anomalies to an end. But the present climate simulations also suggest a possible negative feedback of the associated oceanic heat flux anomalies to the atmospheric circulation, that may react by increasing the zonal circulation and accelerating the Western Boundary Currents again, thereby contributing to a shortening of the LMM at high latitudes in both ocean basins.

\section{Conclusions}

The climate simulation described in the previous section represents a contribution to the reconstruction of the climate of the last centuries, complementary to the climate reconstructions derived from the analysis of proxy data. Of course, to gain a more conclusive picture, simulations with other climate models will have to be carried out and analyzed.

From this simulation several conclusions can be derived. Perhaps the most important is that the level of externally forced climate variability is larger than in most of the empirical climate reconstructions, and tends to agree, although not perfectly, with the reconstructions that indicate quite cold conditions throughout the Little Ice Ice and a steep temperature recovery towards the 20th century (ESPER et al., 2002; HUANG et al., 2000). In particular, the temperature trends simulated at the recovery from the LMM are comparable to the simulated and observed temperature trends since the beginning of the industrialization. Therefore, from the model point of view, the 20th global temperature trends are not unprecedented, although the physical origins of the trends in these different periods may be also different . This is consistent with empirical reconstructions of European temperature (LUTERBACHER et al., 2004).

The climate model ECHO-G also reacts more sensitively to variations in the radiative forcing than the energy balance model of CROWLEY (2000), although essentially the same external forcing has been used in both simulations. The sensitivity of the model ECHO$\mathrm{G}$ is however reasonable when compared to the simulated temperature increase of the last 100 years and to the results of other models under IPCC scenarios of climate change. This different sensitivity to changes in the radiative forcing underlines the need of using coupled three dimensional models under transient forcing to better take into account feedback processes and changes in the ocean circulation.

The simulated temperature deviations in Europe around the LMM agree reasonably well with high resolution empirical reconstructions, both indicating colder temperatures in Eastern and Central Europe than near the Atlantic coast. This fact supports to some extent the ability of climate models in simulating climate change 
at regional scales. However, the model simulated colder temperatures, almost globally, in the LMM, a result that may be traced back to the reduced effective insolation. Therefore, a modification of the atmospheric or oceanic circulation would not be strictly necessary to explain colder conditions in particular regions, e.g. Europe. The climate model, however, simulates markedly colder temperatures in the North Atlantic at high latitudes and over Greenland, and to a lesser extent also in the North Pacific, that seem to require changes in the regional circulation patterns. Unfortunately, this point cannot be checked with the empirical reconstruction.

The analysis of the model simulations suggests that one cause for the intensification of the temperature anomalies lies in the weakening of the Western Boundary currents around the LMM, induced by a weakening of the wind-stress forcing, a reflection of the low state North Atlantic Oscillation, at least in the initial phase of the LMM. This result is consistent with the simulations by SHINDELL et al. (2001), and most empirical reconstructions. However, the model simulates a more complex evolution of the NAOI within the LMM than equilibrium simulations are able to represent. A comparison of empirical reconstructions of the strength, and specially of the timing of the Gulf Stream and the Kuroshio current in the LMM would be quite interesting. Also transient simulations with other coupled models might support this connection between solar forcing and intensity of the Western Boundary current systems.

This climate model also simulates large ice cover and sea surface salinity anomalies around the LMM, that are reminiscent of the Great Salinity Anomaly observed in the North Atlantic around 1970 A.D.. In this simulation the ice cover anomalies are not the result of ice advection, as observed in other model simulations (HALL and STOUFFER, 2001), but are created in situ by a reduced ocean convection south of Greenland, the lower solar insolation, and also probably by a reduced heat flux advection by the Gulf Stream. The reduced salinity at the surface, also a consequence of a weakened Gulf Stream, should have only played a minor role in the production of ice-cover anomalies.

Finally, as a word of caution, it has to be noted that the results presented here are the outcome of just one simulation with a state-of-the art climate model. The role of the model internal variability has not been assessed. This would require the analysis of several simulations started from different initial conditions. Also, the uncertainties in the external forcing, mainly solar irradiance and volcanic radiative effects, have not been explored. Although certainly these are important questions, the computing time needed for such analysis along the 500 simulation years is very demanding. Further work is planned to assess these points for certain key periods of the last five centuries.

\section{Acknowledgements}

The German Climate Computing Center (DKRZ) and NEC provided technical support. The gridded European land-based temperature data from the 20th century have been supplied by the Climate Impacts LINK Project (UK Department of the Environment Contract EPG 1/1/16). J.L. was supported by the Swiss NCCR climate program and F. G-R. partially by the Spanish CICYT (REN 2000-0786). The GKSS work was part of the "Climate in Historical Times" Strategic Project of the Helmholtz Society. Part of the analysis was performed in the SFB 512 of the University of Hamburg. B. GARDEIKE prepared some of the diagrams.

\section{References}

Alcoforado, M.J., M.D. Nuñes, J.C. García, J.P. TABORDA, 2000: Temperature and precipitation reconstruction in southern Portugal during the late Maunder Minimum (A.D. 1675-1715). - The Holocene 10, 33-340.

BARRIENDOS, M., 1997: Climatic variations in the Iberian Peninsula during the Late Maunder Minimum (A.D. 16751715): An analysis of data from rogation ceremonies. - The Holocene 7, 105-111.

Bauer, E., M. Claussen, V. Brovkin, A. HuenerBEIN, 2003. -Assessing climate forcings of the Earth system for the past millennium. Geophys. Res. Lett. 30, 1276.

Bertrand, C., M.F. Loutre, A. Berger , 2002: Climate of the last millenium: a sensitivity study. - Tellus 54A, 221244.

Blunier, T., J.A. Chapellaz, J. Scwander, B. StaufFER B, D. RAYNAUD, 1995: Variations in atmospheric methane concentration during the Holocene epoch. - Nature 374, 46-49.

BORISENKOV, Y.P., 1994: Climatic and other natural extremes in the European territory of Russia in the late Maunder Minimum (1675-1715). - In Frenzel B., C. PFISTER, B. GLASER (Eds): Climatic trends and anomalies in Europe 1675-1715. - Gustav Fischer Verlag, Stuttgart, 83-94.

Bradzil, R., P. Dobrovolny, B. Chocolat, J. MunZAR, 1994: Reconstruction of the climate of Bohemia and Moravia in the period of 1675 to 1715 on the basis of written sources. - In Frenzel B., C. Pfister, B. Glaser (Eds): Climatic trends and anomalies in Europe 1675-1715. - Gustav Fischer Verlag, Stuttgart, 110-121.

BRIFFA, K.R., T.J. OSBORN, 2002: Blowing hot and cold. Science 295, 2227-2228.

BRIFFA, K.R., P.D. JONES, F.H. SChweIngruber, T.J. OSBORN, 1998: Influence of volcanic eruptions on $\mathrm{NH}$ summer temperature over the past 600 years. - Nature 393, 450-455.

COOK, E.R., R.D. D'Arrigo, M.E. MANN, 2002: A well verified, multiproxy reconstruction of the Winter North Atlantic Oscillation Index since A.D. 1400. - J. Clim. 15, 1574-1764.

Crowley, T.J., 2000: Causes of climate change over the past 1000 years. - Science 289, 270-277. 
Cubasch, U., R. Voss, 2000: The influence of total solar irradiance on climate. - Space Science Reviews 94, 185198.

Cubasch, U., G.C. Hegerl, R. Voss, J. Waszkewitz, T.J. CROWLEY, 1997: Simulation with an O-AGCM of the influence of variations of the solar constant on the global climate. - Clim. Dyn. 13, 757-767.

DRUFFEL, E.R.M., S. GRIFFIN, 1993: Large variations of surface ocean radiocarbon: evidence of circulation changes in the southwestern Pacific. - J. Geophys. Res. 98, 2024920259.

Dunbar, R.B., J.E. COLE, 1993: Coral Records of Ocean-Atmosphere Variability. NOAA Climate and Global Change Program. - Special Report No. 10, UCAR, Boulder, $37 \mathrm{pp}$.

EDDY, J.,1976: The Maunder Minimum. - Science 19, 11891202.

Esper, J., E.R. CoOK , F.H. Schweingruber, 2002: Low-frequency signals in long tree-ring chronologies for reconstructing past temperature variability. - Science $\mathbf{2 9 5}$, 2250-2253.

ETHERIDGe, D., L.P. Steele, R.L. LANGenfelds, R.J. FRANDCEY, J.M. BARNOLA, V.I. MORGAN, 1996: Natural and anthropogenic changes in atmospheric $\mathrm{CO}_{2}$ over the last 1000 years from air in Antarctic ice and firn. - J. Geophys. Res. 101, 4115-4128.

FRITTS, H.C., J.M. Lough, 1985: An estimate of average annual temperature variations for North America, 16021961. - Clim. Change 7, 203-224.

Fyfe, J.C., G.J. Boer, G.M. Flato, 1999: The Arctic and Antarctic oscillations and their projected changes under global warming. - Geophys. Res. Lett. 26, 1601-1604.

Ge, Q., J. Zheng, X. FAng, Z. Man, X. Zhang, P. ZHANG, W.-C. WANG, 2003: Winter half-year temperature reconstructions for the Middle and Lower reaches of the Yellow River and Yangtze river during the past 2000 years. - The Holocene 13, 933-940.

GIORGI, F., R. FRANCISCO, 2000: Uncertainties in regional climate change prediction: a regional analysis of ensemble simulations with the HADCM2 coupled AOGCM. - Clim. Dyn. 16, 169-182.

GLASER, R., 2001: Klimageschichte Mitteleuropas: 1000 Jahre Wetter, Klima, Katastrophen. - Primus Verlag, Darmstadt, $227 \mathrm{pp}$.

GLUECK, M. F., C.W. Stockton, 2001: Reconstruction of the North Atlantic Oscillation, 1429-1983. - Int. J. Climatol. 21, 1453-1465.

Hall, A., R.J. Stouffer, 2001: An abrupt climate event in a coupled ocean-atmosphere simulation without external forcing. - Nature 409, 171-174.

Hastenrath S., L. Greischar, 2001: The North Atlantic oscillation in the NCEP-NCAR reanalysis. - J. Clim. 14, 2404-2413.

Hegerl G.C., K. Hasselmann, U. Cubasch, J.F.B. Mitchell, E. Roeckner, R. Voss, J. WASZKeWitZ, 1997: Multi-fingerprint detection and attribution analysis of greenhouse gas, greenhouse gas-plus-aerosol and solar forced climate change. - Clim. Dyn. 13, 613-634.

Holmgren, K., W. Karlen, S.E. Lauritzen, J.A. LeeThorp, T.C. Partidge, S. Pikeh, P. Repinski, C.
Stevenson, O. SVAnered, P.D. Tyson, 1999: A 3000year high-resolution stalagmite-based record of paleoclimate for northeastern South Africa. - The Holocene 9, 295309.

Huang, S.H., H.N. Pollack, P.Y. Shen PY, 2000: Temperature trends over the past five centuries reconstructed from borehole temperatures. - Nature 403, 756-758.

IPCC (INTERGOVERMENTAL PANEL ON Climate CHANGE), 2001: Climate Change: working group 1, the scientific basis. World Meteorological Organization. Available from www.grida.no/climate/ipcc tar

Jones, P.D., K.R. BRIFFA, T.P. BARNeTt, S.F.B. TetT, 1998: High-resolution palaeoclimatic records for the last millennium: interpretation, integration and comparison with General Circulation Model control-run temperatures. - The Holocene 8, 455-471.

Jones, P.D., M. New, D.E. Parker,S. Martin, G. RigORI, 1999: Surface air temperature and its changes over the past 150 years. - Rev. Geophys. 37, 173-199.

JONES, P.D., T.J. OSBORN, K.R. BRIFFA , 2001: The evolution of climate over the last millenium. - Science 292, 662-667.

KOSLOWSKI, G., R. GLASER, 1999: Variations in reconstructed ice winter severity in the Western Baltic from 1501 to 1995, and their implications for the north Atlantic oscillation. - Clim. Change 41, 175-191.

LEAN, J., J. BeER, R. BRADLEY, 1995: Reconstructions of solar irradiance since 1610 - implications for climate change. - Geophys. Res. Lett. 22, 3195-3198.

LEGRAND, J.-P., M. LE GOFF, 1992: Les observations météorologiques de Louis Morin entre 1670 et 1713. - In Direction de la Météorologie Nationale, Monographie Nr. 6, Meteo-France, Trappes, 35 pp.

LegutKe, S., R. Voss, 1999: The Hamburg AtmosphereOcean Coupled Circulation Model ECHO-G. - Technical Report No. 18, DKRZ, Hamburg, 61 pp.

Luterbacher, J., R. RiCKli, E. XOPlaki, Y.C. Tinguel, C. Beck, C. Pfister, H. WAnner, 2001: The Late Maunder Minimum (1675-1715). - A key period for studying decadal scale climatic change in Europe. - Clim. Change 49, 441-462.

Luterbacher, J., E. Xoplaki, D. Dietrich, R. Rickli, J. Jacobeit, C. BeCK, D. Gyalistras, C. Schmutz, H. WANNER, 2002a: Reconstruction of Sea Level Pressure fields over the Eastern North Atlantic and Europe back to 1500. - Clim. Dyn. 18, 545-561.

Luterbacher, J., E. XOPlaKi, D. Dietrich, P.D. Jones, T.D. DAVIES, D. Portis, J.F. GonzÁlezRouco, H. von Storch, D. Gyalistras, C. Casty, H. WANNER, 2002b: Extending North Atlantic Oscillation reconstructions back to 1500. - Atmos. Sci. Lett. 20, 114124.

Luterbacher, J., D. Dietrich, E. Xoplaki, M. GrosJEAN, H. WANNER, 2004: European seasonal and annual temperature variability: trends and extremes since 1500. Science 303, 1499-1503.

MANN, M.E., R.S. BRADLEY, M.K. HugheS, 1998: Global-scale temperature patterns and climate forcing over the past six centuries. - Nature 392, 779-787.

$-, \ldots, \ldots, 1999$ : NH temperatures during the past millennium: Inferences, uncertainties, and limitations. - Geophys. Res. Lett. 26, 759-762. 
Mann, M.E., S. Rutherford, R.S. Bradley, M.K. Hughes, F.T. KeIMING, 2003: Optimal surface temperature reconstructions using terrestrial borehole data. - J. Geophys. Res. 108 (D7), 4203.

Mannley, G., 1974: Central England temperatures monthly means 1659 to 1973. - Quart. J. Roy. Meteor. Soc. 100, 389-405.

MYSAK, L.A., D.K. MAnaK, R.F. MARsden, 1990: Seaice anomalies observed in the Greenland and Labrador seas during 1901-1984 and their relation to an interdecadal Arctic climate cycle. - Clim. Dyn. 5, 111-133.

OGILVIE, A.E.J., 1996: Sea ice conditions off the coasts Iceland A. D. 1601-1850 with special reference to part of the Maunder Minimum period (1675-1715). AmS-Varia 25, Archaeological Museum of Stavanger, Norway, 9-12. Part II: Development of 1901-1996 monthly grids of terrestrial surface climate. - J. Climate 13, 2217-2238.

Pfister, C., R. Bradzil, R. Glaser, M. BARriendos, D. CAmuffo, M. Deutsch, P. Dobrovolny, S. EnzI, E. Guidoboni, O. Kotyza, S. Militzer, L. Racz, F.S. RODRIGO, 1999: Documentary evidence on climate in sixteenth-century Europe. - Clim. Change 43, 55-110.

Quinn, T.M., T.J. Crowley, F.W. TAYlor, C. Henin, P. JOANNOT, Y. JOIN Y, 1998: A multicentury isotopic record from a New Caledonia coral: Interannual and decadal sea surface temperature variability in the southwest Pacific since 1657 A.D. - Paleoceanography 13, 412-426.

Robertson A., J. Overpeck, D. Rind, E. MosleyThompson, G. Zielinski, J. LEAN, D. KOCH, J. PENNer, I. TEgen, R. Healy, 2001: Hypothesized climate forcing time series for the last 500 years. - J. Geophys. Res. 106, 14783-14803.

Roeckner, E., K. Arpe, L. Bengtsson, M. Christoph, M. Claussen, L. DüMenil, M. Esch, M. Giorgetta, U. Schlese, U. SchulzweidA, 1996: The atmospheric general circulation model ECHAM4: Model description and simulation of present-day climate. - MPI Report No. 218, Max-Planck-Institut für Meteorologie, Hamburg, Germany, 90 pp.

Schmutz, C., J. Luterbacher, D. Gyalistras, E. XoPLAKI, H. WANNER, 2000: Can we trust proxy-based NAO index reconstructions? - Geophys. Res. Lett. 27, 11351138.

Shindell, D.T., R.L. Miller, G.A. Schmidt, L. PANDOLFO, 1999: Simulation of recent northern winter climate trends by greenhouse-gas forcing. - Nature 399, 452-455.

Shindell, D.T., G.A. Schmidt, M.E. MAnN, D. Rind, A. WAPLE, 2001: Solar forcing of regional climate change during the maunder minimum. - Science 294, 2149-2152.

SLONOWSKI, V.C., P.D. JONES, T.D. DAVIES, 2001: Instrumental pressure observations and atmospheric circulation from the 17th and 18th centuries: London and Paris. - Int. J. Climatol. 21, 285-298.

STOCKER, T.F, 2002: North-south connections. - Science 297, 1814-1815.
Stott, P. A., S.F.B. Tett, G.S., M.R. Allen, J.F.B. Mitchell, G.J. JenKins, 2000: External control of 20th century temperature variations by natural and anthropogenic forcings. - Science 15 2133-2137.

Tyson, P.E., W. Karlen, K. Holmgren, G.A. Heiss, 2000: The Little Ice Age and medieval warming in South African. - S. Afr. J. Sci. 96 121-126.

Ulbrich, U., M. Christoph, 1999: A shift of the NAO and increasing storm track activity over Europe due to anthropogenic greenhouse gas forcing. - Clim. Dyn. 15, 551$\underline{559 .}$

VAN DEN DoOL H.M., H.J. KRIJNEN, C.J.E. SCHUURMANS, 1978: Average winter temperatures at De Bilt (The Netherlands): years 1634-1977. - Clim. Change 1, 319330.

VAn Engelen, A.F.V., J. Buisman, F. IJnsen, 2001: A millennium of Weather, Winds and Water in the Low Countries. - In: JONES, P. D. et al. (Eds): History and Climate: Memories of the Future?, Kluwer Academic Press, New York, Boston, London, 101-124.

Villalba, R., A. Lara, J.A. Bonisegna, J.C. AreANA, F. Roig, A. Schmelter, S. Delgado, A. WoloDARSKY, A. RIPLATA, 2002: Large-scale temperature changes across the southern Andes: 20th-century variations in the context of the past 400 years. - Clim. Change 59, 177-232.

Wang, S.,D. Gong, J. ZHU, 2001: Twentieth-century climatic warming in China in the context of the Holocene. The Holocene 11, 313-321.

WANner H.,C. Pfister, R. Bradzil, P. Frich, K. FryDENDAhl, T. Johnsson, J. Kington, H.H. LAMB, S. ROSENORN, E. WiSHMANE, 1995: Wintertime European circulation patterns during the Late Maunder Minimum cooling period (1675-1704). - Theor. Appl. Climatol. 51, $167-175$.

WOLFF, J.-O., E. MAIER-Reimer, S. LegutKe, 1997: The Hamburg Ocean Primitive Equation Model. - Technical report No. 13, German Climate Computer Center (DKRZ), Hamburg, 98 pp.

Xoplaki, E. , P. MAHeras, J. Luterbacher, 2001: Variability of climate in Meridional Balkans during the periods 1675-1715 and 1780-1830 and its impact on human life. Clim. Change 48, 581-615.

YAnG, B., A. Braeuning, KR. Johnson, Y.F. Shi S, 2002: General characteristics of temperature variations in China during the last two millenia. - Geophys. Res. Lett. 29, 1324.

ZoritA, E., J.F. GonZÁLEZ-Rouco, 2000: Disagreement between predictions of the future behavior of the Arctic Oscillation as simulated in two different climate models: implications for global warming. - Geophys. Res. Lett. 27, 1755-1758.

—, - 2002: Are temperature-sensitive proxies adequate for North Atlantic oscillation reconstructions? - Geophys. Res. Lett. 29, 48-1, 48-4. 